\title{
Las aguas subterráneas del Parque Nacional de la Sierra de Guadarrama
}

\author{
Javier G. Yélamos ${ }^{(1)}$, Eugenio Sanz Pérez ${ }^{(2)}$ y José Ignacio Escavy Fernández ${ }^{(3)}$ \\ (1) Departamento de Geología y Geoquímica. Universidad Autónoma de Madrid. Campus de Cantoblanco. 28049 Madrid. \\ javier.yelamos@uam.es \\ (2) Departamento de Ingeniería y Morfología delTerreno, ETSICCP, Universidad Politécnica de Madrid. 28040 Madrid. \\ esanz@caminos.upm.es \\ (3) Departamento de Ingeniería y Morfología delTerreno, ETSICCP, Universidad Politécnica de Madrid. 28040 Madrid. \\ ji.escavy@upm.es
}

\begin{abstract}
RESUMEN
El Parque Nacional de la Sierra de Guadarrama se extiende sobre casi $1000 \mathrm{~km}^{2}$ de las zonas más elevadas de esa sierra en las provincias de Madrid y Segovia. Su litología está dominada por rocas plutónicas y metamórficas (hard rocks) salvo la fosa sedimentaria del Alto Valle del Lozoya. Aquellos materiales son prácticamente impermeables, pero dan lugar a pequeños acuíferos locales, someros y de bajos recursos por alteración superficial, fracturación y depósitos recientes de escasa entidad, como coluviones, aluviones, morrenas y conos de deyección. Los estudios del túnel del tren de alta velocidad que atraviesa el Parque, confirman la casi nula permeabilidad en profundidad, pero muestran la posibilidad de la existencia de un flujo profundo a través del conjunto de las discontinuidades del macizo rocoso que se puede corresponder al modelo propuesto por Toth en los años 60. Las calizas de la fosa del alto Lozoya dan lugar a un acuífero libre y kárstico, que ha sido un tanto olvidado en los estudios hidrogeológicos previos, pero con puntos de agua capaces de aportar caudales de decenas de L/s. A pesar de los escasos recursos subterráneos de estas hard rocks, los acuíferos locales han jugado un papel destacable en el abastecimiento a las poblaciones, facilitan las actividades de recreo alimentando fuentes por todo el Parque, dan de beber al ganado de la zona y juegan un importante papel ecológico de mantenimiento de las masas de agua en periodos de estiaje. Asociada a esa circulación profunda aparecen varios manantiales de aguas sulfurosas, mientras que la buena calidad de las aguas de los acuíferos someros ha permitido el establecimiento de varias plantas embotelladoras de aguas minerales naturales.
\end{abstract}

Palabras clave: Parque Nacional de Guadarrama, hidrogeología, acuíferos en hard rocks, Sistema Central Español, aguas minerales.

\section{Groundwater in the Guadarrama Range National Park}

\begin{abstract}
The Guadarrama Range National Park covers about $1000 \mathrm{~km}^{2}$ of the highest areas of this mountain range in the provinces of Madrid and Segovia. The most abundant lithologies are igneous and metamorphic rocks (hard rocks) except in the sedimentary basin in the High Valley of Lozoya. These rocks are practically impervious but can host small local, shallow and low-resource aquifers by processes of surface alteration, fracturing, and recent deposits of small size such as colluviums, alluviums, moraines and talus cones. Works on the tunnel for the high speed train that crosses beneath the Park, confirm the almost null permeability in depth but show the possibility of the existence of a deep flow through the set of discontinuities within the rock massif that may correspond to the model proposed by Toth in the 1960s. Limestone in the Lozoya basin give rise to a water table and karstic aquifer, which has been somewhat forgotten in previous hydrogeological studies, but it has water points with flow at rates of tens $L / s$. In spite of the poor water resources of hard rocks, local aquifers have played a significant role in the drinking water supply to localities in the area, enabling recreational activities with drinking fountains throughout the Park, supplying water to the livestock, and playing a key ecological role in maintaining water bodies during the summer. There are several springs of sulphurous waters resulting from deep groundwater flow, while the good quality water in the shallow aquifers has allowed the establishment of some bottling plants of natural mineral waters.
\end{abstract}

Keywords: Guadarrama Range National Park, hydrogeology, hard rock aquifers, Spanish Central System, mineral water. 
Javier G. Yélamos, et al., 2019. Las aguas subterráneas del Parque Nacional de la... Boletín Geológico y Minero, 130 (4): $743-772$

\section{Introducción}

En la mayor parte de la superficie del Parque Nacional de la Sierra de Guadarrama (en adelante PNG) afloran rocas plutónicas y metamórficas, a las que en los contextos hidrogeológicos se les denomina como "hard rocks"; estas "rocas compactas" se caracterizan por dar lugar a acuíferos pobres, amén de resultar su estudio bastante complejo, no siendo útiles algunas de las metodologías hidrogeológicas convencionales. La suma de estos dos factores ha dado lugar a que este tipo de materiales sean tradicionalmente dejados de lado en los estudios hidrogeológicos, asignándoles la etiqueta de "impermeables a efectos prácticos o con acuíferos de interés local". De hecho, hoy en día una buena parte de las hard rocks de la Península lbérica ni siquiera están definidas como masas de aguas subterráneas, tal como acontece con el sector madrileño de las que ocupan el PNG. Sin embargo en las últimos décadas, las hard rocks del Sistema Central han sido objeto específico de tesis doctorales (Yélamos, 1991, Martín-Loeches, 1995); en ellas estableció ENRESA el laboratorio subterráneo del Berrocal (ENRESA, 1996) y, especialmente, en la zona del PNG, se ha obtenido una gran información a partir de los estudios previos y resultados del doble túnel de $28 \mathrm{~km}$ de largo que atraviesa el Parque para servicio del tren de alta velocidad (en adelante TAV) de la línea Madrid-Galicia.

En las páginas siguientes se exponen estos avances en el conocimiento de la hidrogeología de las rocas plutónicas y metamórficas del PNG y a la vez se muestra que, a pesar de sus limitados recursos, juegan su papel más relevante de lo que cabría esperar si tan solo se consideran los volúmenes de agua que ponen en juego.

\section{Características generales del Parque Nacional de la Sierra de Guadarrama}

El Parque Nacional de la Sierra de Guadarrama está situado dentro de las alineaciones montañosas del Sistema Central, y más en concreto en su parte central, la Sierra de Guadarrama. Su extensión es de 33960 ha de las cuales dos tercios corresponden a la Comunidad de Madrid (21714 ha) mientras que las restantes 12426 ha se extienden sobre la Comunidad de Castilla y León, íntegramente dentro de la provincia de Segovia (Fig. 1). Bordeando el PNG se establece una zona de protección que cubre 62655 ha, repartida a partes más o menos similares entre las provincias de Madrid y Segovia, formando una banda sobre el área del parque y extendiéndose principalmente sobre los cursos altos de los ríos Lozoya y Eresma. En tercer lugar, los municipios que tienen parte de su territorio afectado por alguno de los dos límites anteriores dan lugar a lo que se denomina Área de Influencia Socioeconómica (cfr. España, 2013a)

Según refiere Palacios y Andrés de Pablo (2005) el clima del PNG es el característico de la alta montaña mediterránea, con ciertos rasgos continentales. Considerando los datos de la estación del Puerto de Navacerrada, situada a unos 1800 m de altitud, límite inferior de los espacios supraforestales, la temperatura media anual es de $6.1^{\circ} \mathrm{C}$, y durante tres meses (diciembre a febrero), la temperatura media es menor de $0{ }^{\circ} \mathrm{C}$; de Noviembre a abril, la temperatura mínima media mensual es inferior a $0{ }^{\circ} \mathrm{C}$. Las precipitaciones superan los $1400 \mathrm{~mm} / a$ ño, las cuales se concentran desde primeros de octubre a finales de mayo, con máximos a principios de otoño y comienzos de invierno, con un máximo secundario en primavera. El verano es árido, y entre julio y agosto la precipitación es de $53 \mathrm{~mm}$ de media, concentradas en solo seis días. Los temporales de lluvia y nieve están condicionados por situaciones del oeste, y las olas de frio son del $\mathrm{NE}$, que no dejan tanta nieve como las del oeste.

\section{Marco geológico}

El Sistema Central, sistema montañoso al que pertenece la Sierra de Guadarrama, es una cadena alpina flanqueada por la Cuenca del Tajo al sur y la del Duero al norte (Fig. 2). El levantamiento de las rocas precámbricas y paleozoicas que forman la sierra se produjo debido al régimen compresivo durante el Paleógeno y Neógeno, resultando en un gran pop-up formado por varios bloques levantados entre fallas inversas conjugadas (Capote, 2005).

Las rocas dominantes en la Sierra de Guadarrama son metamórficas (Fig. 3a), sobre todo gneis glandular y leuconeis derivados del metamorfismo de granitos preexistentes (Capote, 2005). También abundan los metasedimentos generados por el metamorfismo de antiguos sedimentos de variada naturaleza resultando en esquistos y rocas de silicatos cálcicos. EI metamorfismo de estas rocas se produjo en la orogenia Varisca con un evento principal de recristalización entre los 390 y los $326 \mathrm{Ma}$ donde se alcanzaron condiciones de "Grado Alto" (temperaturas de $700^{\circ}$ y presiones confinantes de $8.5 \mathrm{Kbar}$ ). Las rocas metamórficas se encuentran intruídas por grandes masas de rocas plutónicas graníticas entre las que destacan las adamellitas y leucogranitos, como en el batolito de La Pedriza (Fig. 3b), el cual ya estaba incluido dentro de otra zona protegida antes del establecimiento del 


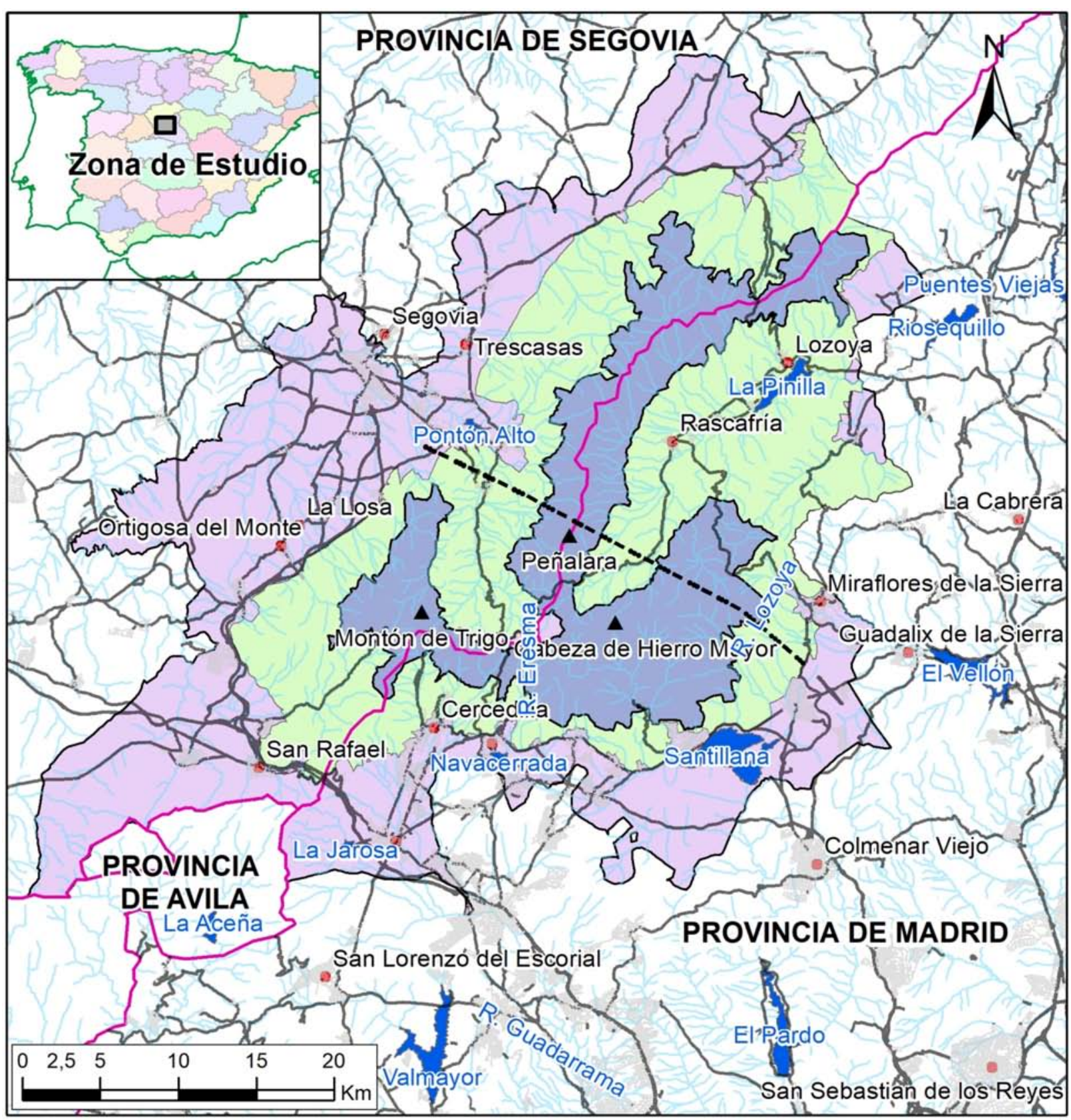

\section{Leyenda}

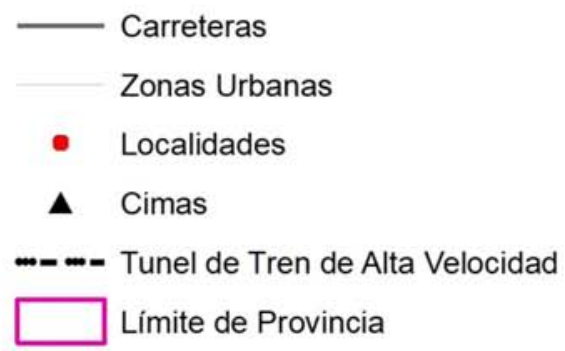

Embalses

Red Fluvial

Parque Nacional de la Sierra de Guadarrama

Zona Periférica de Protección P.N.S. Guadarrama

Área de Influencia Socioeconómica del P.N.S. Guadarrama

Figura 1. Situación geográfica y zonación del Parque Nacional de la Sierra de Guadarrama.

Figure 1. Geographical location and zonation of the Guadarrama Range National Park. 


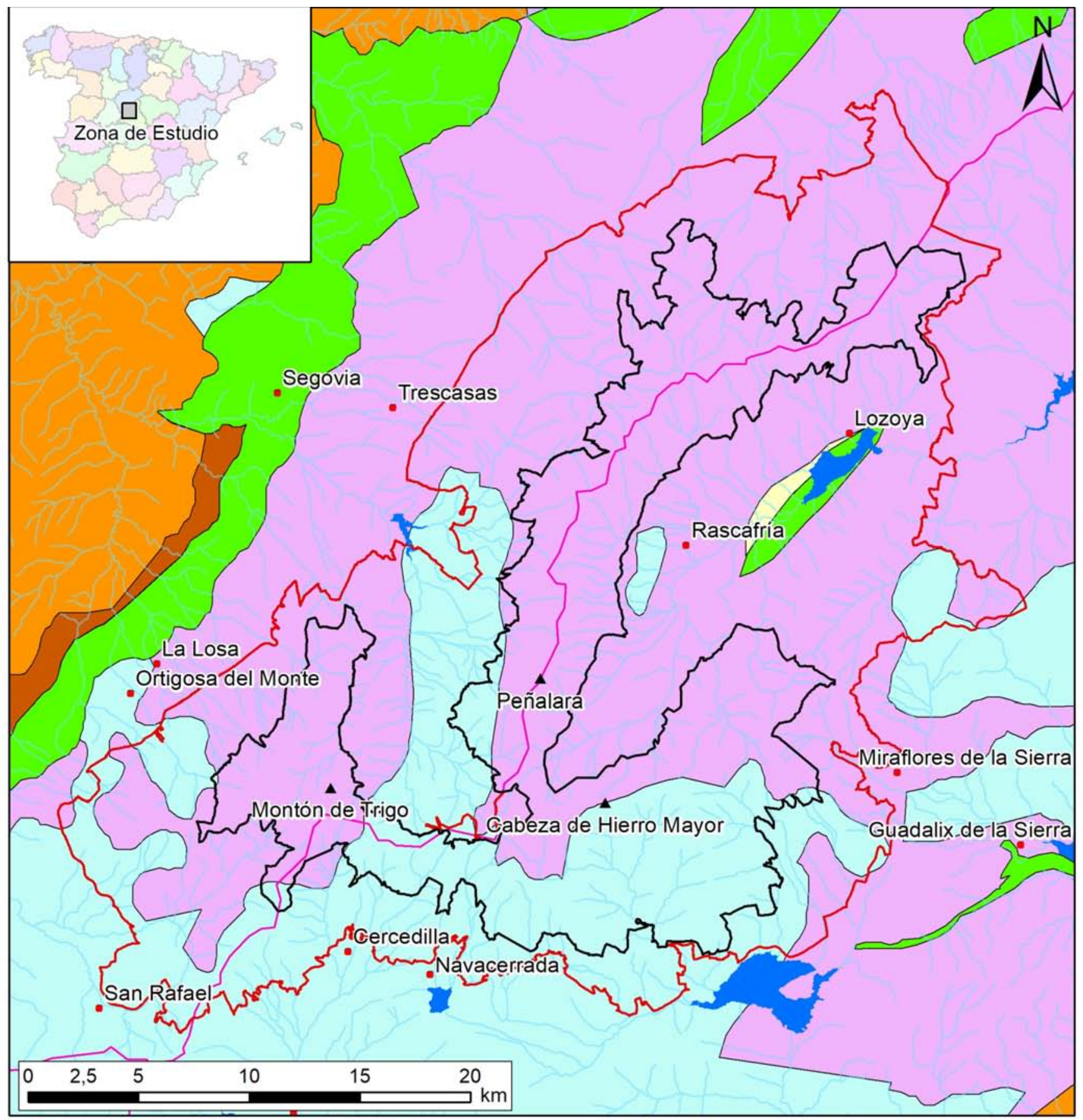

\section{Leyenda}

\begin{tabular}{|c|c|c|c|}
\hline & Parque Nacional de la Sierra de Guadarrama & Límite Provincial & Rocas Paleógenas \\
\hline & Zona Periférica de Protección P.N.S. Guadarrama & Red Fluvial & Rocas Cretácicas \\
\hline - & Localidades & Sed. Cuaternarios AVL & Granitoides \\
\hline$\Delta$ & Picos & Rocas Neógenas & Metasedimentos \\
\hline
\end{tabular}

Figura 2. Mapa geológico simplificado del PNG.

Figure 2. Simplified geologic map of PNG. 


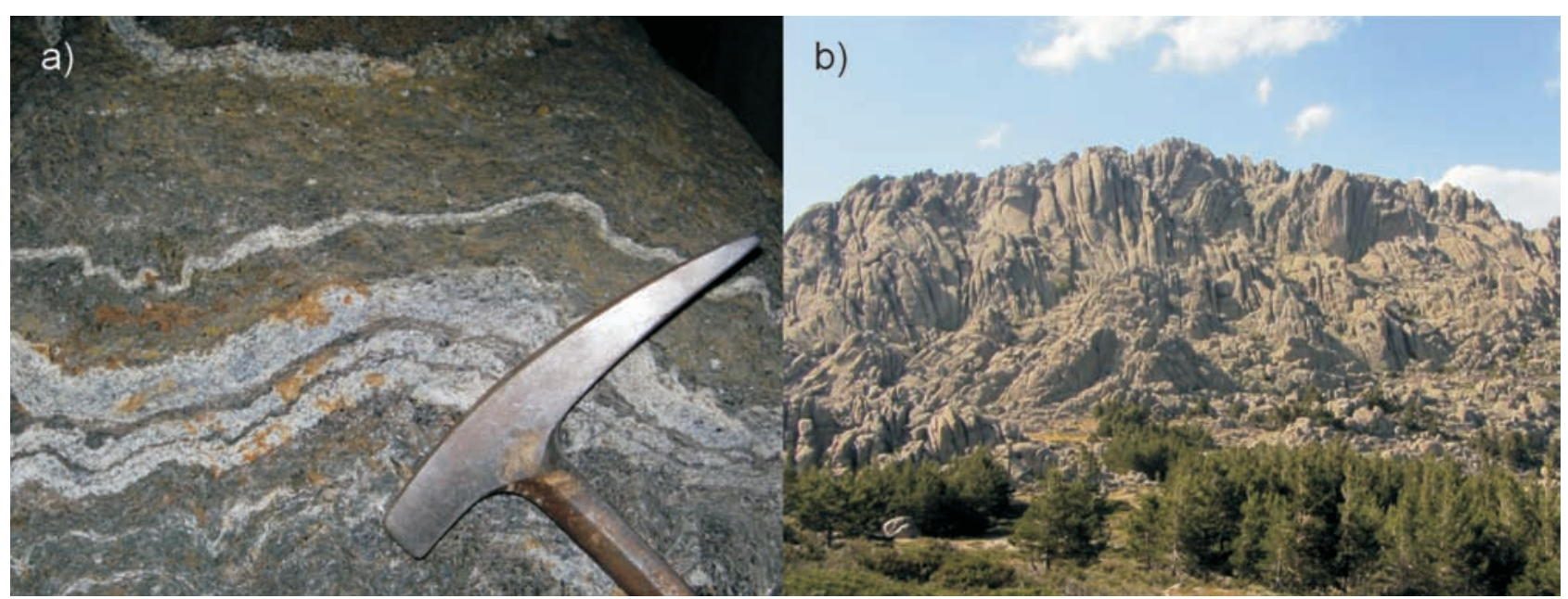

Figura 3. Principales tipos de rocas que afloran en el PNG. a) Metamórficas, en la imagen neises bandeados. b) Granitos con diaclasado vertical en la Pedriza.

Figure 3. The two main types of rocks that can be found in the PNG. a) Metamorphic, in the picture is shown banded gneiss. b) Granitic rocks with a vertical joints set in the Pedriza.

PNG: el Parque Regional de la Cuenca Alta del Manzanares.

El emplazamiento de los granitoides se produjo durante el Carbonífero Superior y el Pérmico Inferior. Además, abundan en la Sierra de Guadarrama rocas filonianas formando enjambres de edades y composiciones muy diversas tales como diques de pórfido, lamprófidos, microdioritas o cuarzo. Localmente los granitos aparecen alterados por fluidos hidrotermales pérmicos formando rocas que se han venido denominando como episienitas.

En el fondo del Alto Valle del Lozoya (en adelante AVL) afloran materiales mesozoicos y cenozoicos (ITGE, 1991). Los materiales mesozoicos, están compuestos en su base por cerca de $40 \mathrm{~m}$ de depósitos siliciclásticos (areniscas, lutitas, y conglomerados) de edad Coniaciense Medio-Superior con rasgos típicos de depósitos litorales que indican una transgresión marina sobre el zócalo paleozoico. Sobre estos materiales aparecen hasta $30 \mathrm{~m}$ de cuerpos tabulares detrítico-dolomíticos alternando con niveles margosos que han sido datados como Coniaciense SuperiorSantoniense Inferior. Estos materiales se han formado en un ambiente de plataforma continental dando en la actualidad morfologías tipo cuesta con presencia de cavidades cársticas (Karampaglidis et al. 2012). Sobre estos se depositó una serie detrítica siliciclástica (areniscas con cemento dolomítico) de hasta $60 \mathrm{~m}$ de espesor en la que también se pueden encontrar algunas construcciones arrecifales de rudistas $y$ estromatolitos (ITGE, 1991). Estos materiales se han formado en un ambiente de plataforma somera de alta energía durante el Santoniense Medio-Superior.
El Cretácico termina en el Valle del Lozoya con una secuencia de areniscas con cemento dolomítico típicas de plataformas continentales someras con episodios de exposición subaérea.

El Cenozoico está representado en el AVL por materiales tanto del Paleógeno como del Cuaternario. Los depósitos paleógenos están compuestos por hasta $60 \mathrm{~m}$ de conglomerados y areniscas depositados en zonas proximales de abanicos aluviales (ibídem, 1991). Sólo en la zona Oeste del Valle del Lozoya aparecen materiales Neógenos, principalmente depósitos detríticos de granulometría gruesa. EI Cuaternario está formado por sedimentos detríticos compactos con granulometrías en general gruesas (bloques y cantos) que se han acumulado en antiguos conos de deyección y en terrazas fluviales.

Con respecto a la fracturación de los materiales, muchas de las fallas que facilitaron los movimientos durante la tectónica Alpina se formaron en el período tectónico denominado Tardivarisco, momento en el que las rocas sufrieron una intensa fracturación y la formación de grandes fallas (Capote, 2005). Estas grandes fracturas pueden tener un papel importante en la hidrogeología de la zona, ya que son vías posibles de circulación de agua subterránea en los materiales impermeables del basamento. Desde el punto de vista hidrogeológico, las fallas de la zona están formadas por un núcleo de material triturado y alterado, en general arcilloso e impermeable, flanqueado por una zona de daño, en la que las rocas aparecen fracturadas más intensamente cuanto más cerca del núcleo. La anchura y geometría de la zona de daño es muy variable. 
Javier G. Yélamos, et al., 2019. Las aguas subterráneas del Parque Nacional de la... Boletín Geológico y Minero, 130 (4): $743-772$

\section{Hidrogeología del PNG}

\section{Introducción}

En los materiales plutónicos y metamórficos de la vertiente madrileña de la Sierra de Guadarrama no se reconoce oficialmente ninguna masa de agua subterránea (CHT, 2015); cabe suponer que de forma implícita se les caracteriza con el código 99 utilizado en el primer mapa de unidades hidrogeológicas (SGOPITGE, 1991) que significaba áreas impermeables con o sin acuíferos aislados de interés muy local; en cambio para la vertiente norte, la Confederación del Duero ha denominado a los materiales plutónicos y metamórficos en su sector del PNG dentro de la masa de aguas subterránea número 54, DU-40054 Guadarrama Somosierra (España, 2013b).

En cualquier manual de hidrogeología siempre se indica lo mismo en relación a las aguas subterráneas en rocas plutónicas y metamórficas: materiales impermeables en la práctica que pueden dar lugar a una circulación de aguas subterráneas a favor de procesos de fracturación y alteración superficial. Si una de las zonas alteradas alcanzara una suficiente entidad como para ser definida y cartografiada, en tal caso saldría del contexto de las hard rocks, tratándose de un acuífero con porosidad intergranular.

Los caudales en juego en las hard rocks del PNG son muy discretos. A partir del inventario de puntos de agua de Yélamos (1991) los caudales de pozos y manantiales suelen ser inferiores a $1 \mathrm{~L} / \mathrm{s}$ y más que aceptables las captaciones capaces de llegar al final del estío con un continuo de $0.1 \mathrm{~L} / \mathrm{s}$.

Las rocas que afloran dentro del PNG han sufrido esos dos tipos de procesos: fracturación durante las dos orogenias que han intervenido en su formación y los procesos recientes de alteración en superficie. Además de los pequeños acuíferos formados mediante procesos de alteración también hay otros tipos de formaciones superficiales que dan lugar a acuíferos someros de escasa entidad. El conjunto de estos, junto con la red de fracturas y diaclasas más superficiales entran en lo que se va a denominar como acuíferos someros en los que, a grandes rasgos, la circulación del agua subterránea no tiende a ir más allá de la decena de metros de profundidad.

\section{Acuíferos someros en hard rocks}

Con el adjetivo someras se hace referencia a las aguas subterráneas en las hard rocks cuya circulación acontece en los primeros metros del subsuelo. En este contexto entran los acuíferos por fracturación en los que los planos de discontinuidad tienen una escasa penetración en el terreno, acuíferos por alteración superficial y un tercer caso son varios tipos de formaciones superficiales de edad Cuaternaria desarrolladas sobre la superficie de las rocas plutónicas y metamórficas.

Los dos últimos tipos de acuíferos tienen en común, en la Sierra de Guadarrama:

a) Escaso espesor, en general escasa entidad y presentan porosidad intergranular.

b) Dan lugar a acuíferos de carácter libre. En principio su recarga es por infiltración eficaz de la lluvia, fusión de nieve en las altas cotas, y tienden a descargar en el contacto con la roca madre fresca, en forma de pequeños manantiales o bien directamente a los cursos de aguas superficiales cuando están en conexión hidráulica con éstos.

c) El tiempo de permanencia circulando por el subsuelo es breve; debe de ser del orden de tan solo meses, raro que se sobrepase el año, tal como lo evidencia el notable descenso de caudal, o incluso agotamiento, que sufren los manantiales y pozos en la Sierra de Guadarrama durante el estío.

La figura 4 muestra un corte en el que se recogen las distintas posibilidades de acuíferos someros y presencia de manantiales. Siguiendo la numeración de la figura, las posibilidades son las siguientes:

1. Materiales porosos por alteración sobre granitos; cuando están en superficie se ven afectados por la acción de los agentes atmosféricos, alterándose feldespatos y micas y dando lugar a un depósito de aspecto arenoso, el denominado como lehm, de pocos metros de espesor. Un sondeo sobre estos materiales suele presentar la siguiente variación de la permeabilidad con la profundidad: a) una zona menos permeable en superficie por la presencia de arcillas, b) incremento de la permeabilidad por la presencia de arenas más lavadas que a su vez pueden estar en contacto con fracturas abiertas y c) finalmente en profundidad, la permeabilidad disminuye a prácticamente nula tras el cierre de las diaclasas y fracturas por el peso de los materiales suprayacentes.

Pequeñas zonas de lehm pueden apreciarse en cualquier punto en el que afloren granitos, pero las principales aparecen en zonas de baja cota y suave relieve. De acuerdo con CAM (1986) las de mayor entidad dentro del sector madrileño del PNG aparecen en el eje Cercedilla-Los Molinos-Guadarrama.

Dentro de estas zonas de lehm con cierta entidad, si la topografía lo permite, se pueden formar lagunas alimentadas por las aguas subterráneas, que a su vez suponen un potencial punto de descarga por evaporación.

2. Depósitos de ladera o coluviones. Dentro de las 


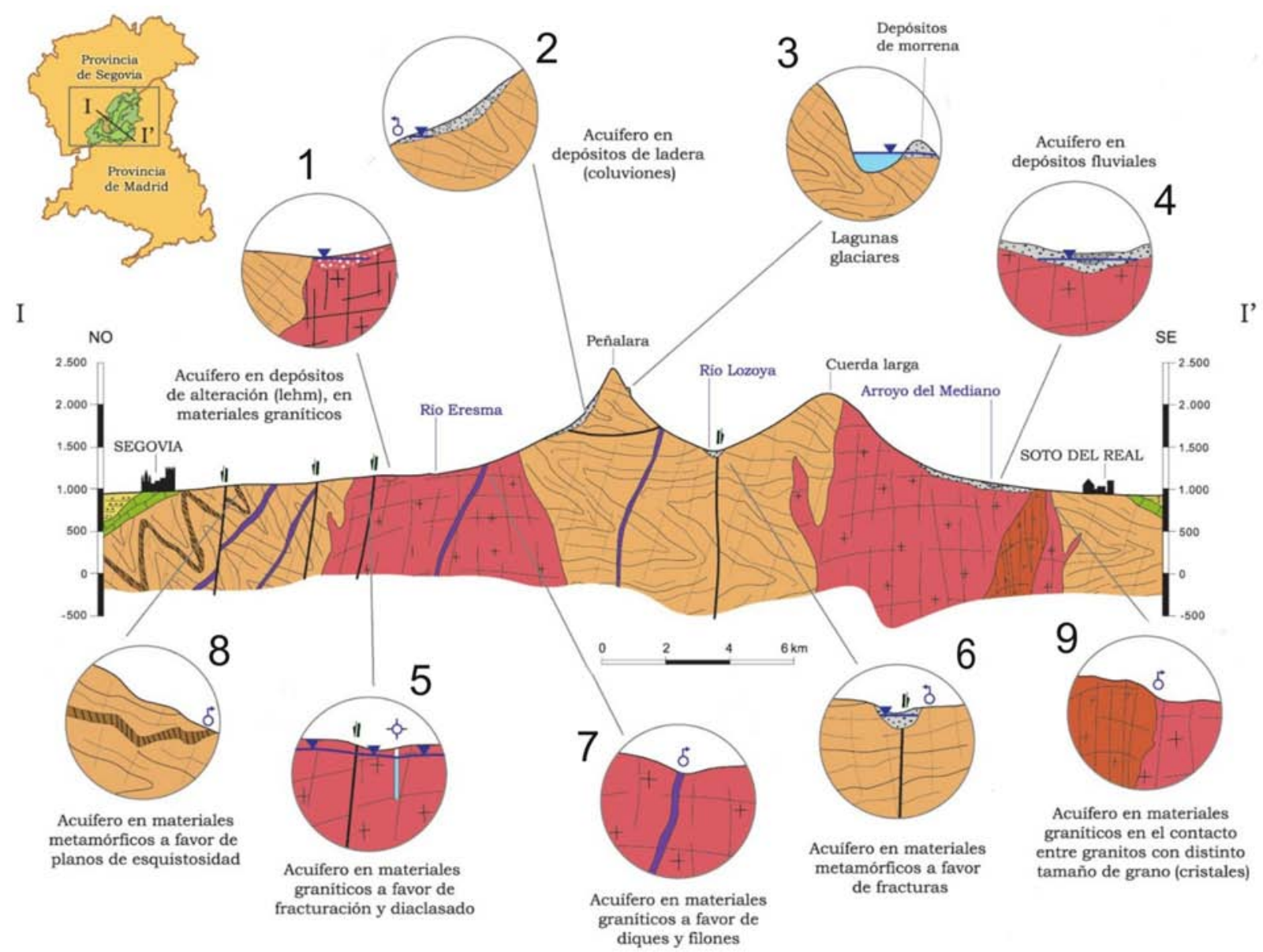

Figura 4. Corte geológico idealizado y detalle de las situaciones de almacenamiento y surgencia de las aguas subterráneas en la Sierra de Guadarrama. Modificado de A. García de Domingo en Mejías et al., 2015.

Figure 4. Conceptual geological cross-section and detailed picture of the storage and spring of groundwater in the Sierra de Guadarrama. Modified from A. García de Domingo in Mejías et al., 2015.

pendientes del PNG aparecen bien representados los canchales y pedreras (Fig. 5a) en zonas elevadas, más frecuentemente en la vertiente segoviana. Estas acumulaciones de rocas están originadas por ciclos hielo/deshielo dando lugar a un manto de pequeño espesor compuesto de cantos y bloques angulosos que dejan numerosos huecos entre ellos. Su recarga a partir de la infiltración de lluvia y fusión de nieve, mientras que la descarga tiene lugar a través de manantiales en el contacto coluvión/roca fresca como en la figura 4.2, o bien a los cauces superficiales que nacen justo en el límite inferior del canchal.

3. Morrenas (Fig. 5b). Acumulaciones de detritos resultado del avance de los discretos glaciares de ladera que hubo en las zonas más altas de la Sierra de Guadarrama, preferentemente en la vertiente madrileña a cotas entre 1800 y 2000 m. Sus espesores son de pocos metros y la morrena de mayor continuidad no supera los $2 \mathrm{~km}^{2}$ de superficie.
Al tratarse de depósitos en los que se mezclan todo tipo de tamaños, con una importante matriz, cabe suponer que su comportamiento hidrogeológico sea más de acuitardo que de acuífero en sentido estricto.

Las morrenas laterales tenderán a tener una descarga por pequeños manantiales y rezumes en el contacto entre la roca fresca erosionada y la morrena. Los arcos morrénicos terminales, diseccionados por los cauces superficiales actuales, pueden descargar directamente hacia estos.

4. Depósitos fluviales o coluviones formados por los sedimentos que van desplazando los cauces fluviales, dando lugar a superficies más o menos planas a distintas cotas: las terrazas fluviales. Las zonas de cumbre y las fuertes pendientes del PNG no son el ámbito más característico para la formación de terrazas, pero sí que se encuentran en las zonas de menor altitud. Según la cartografía MAGNA las principales 


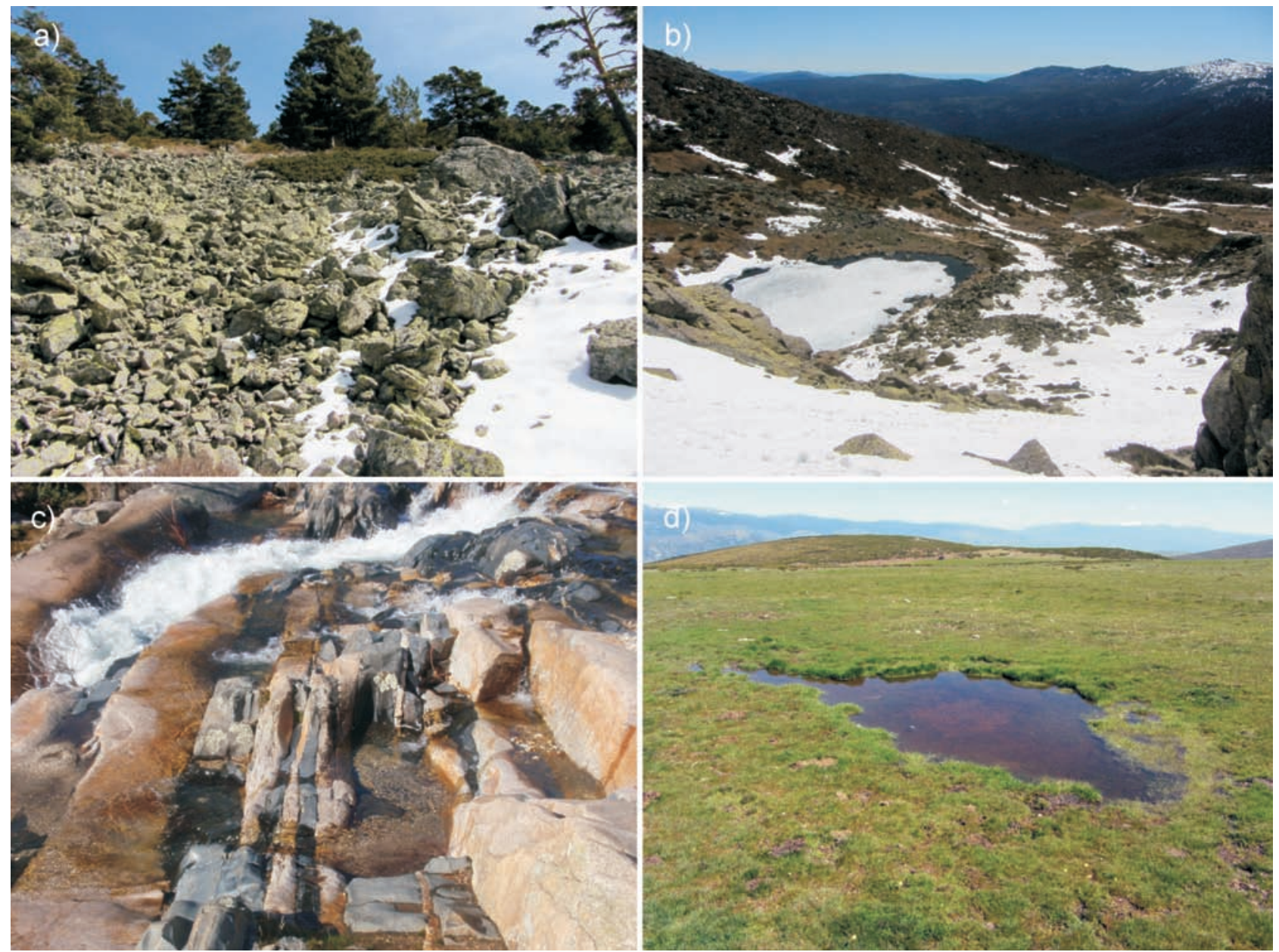

Figura 5. Formaciones geológicas relacionadas con las aguas subterráneas del PNG. a) Canchal en el camino al Puerto de la Fuenfría. b) Circo de Peñalara con arco morrénico y la laguna Grande de Peñalara en primer término. c) Diques de diabasas cortando granitos en el cauce del río Manzanares cerca de la Charca Verde. d) Zona de encharcamiento con turbera en el Collado Abierto de Canencia.

Figure 5. Geological formations related to PNG groundwater. a) Talus in the way to the Fuenfría hill pass. b) Glacial cirque of Peñalara with terminal moraine and the lagoon Grande of Peñalara in the foreground. c) Dykes of diabase crossing granite rocks on the Manzanares river bed near the Charca Verde. d) Waterlogging area with peat bog in the Collado Abierto of Canencia.

aparecen sobre los ríos Peñalara aguas arriba de Valsaín (ITGE, 1998), Guadarrama y su afluente el Tejo a la altura de la localidad del mismo nombre (ITGE, 1990) y, sobre todo, en el tramo llano del AVL, donde se distinguen dos niveles (ITGE, 1998), recubriendo otros sedimentos que forman parte de esta unidad acuífera.

En principio las terrazas están conectadas hidráulicamente con el cauce que las origina, sobre todo cuando solo hay un único nivel de terrazas, de manera que ese será su punto de descarga natural.

Las imágenes 5 y 6 de la figura 4 hacen referencia al mismo tipo de acuíferos, por fracturación, en granitos en el primer caso y sobre rocas metamórficas el diagrama número 6 . Poco se puede decir de éstos salvo que su estudio es sumamente complejo.
Conceptualmente se trata de acuíferos en los que la circulación de las aguas subterráneas acontece a favor de planos de discontinuidad dentro del macizo rocoso que puedan originarse por cualquier mecanismo: fallas, fracturas, diaclasas tectónicas, de descompresión, etc.

Partiendo del anterior supuesto, cabe esperar que la identificación de fracturas puede ser un buen criterio a la hora de ubicar captaciones sobre hard rocks. Obviamente una fractura puede ser una vía de circulación de agua por el subsuelo, pero no basta con la existencia de la estructura planar. Las fracturas hidrológicamente más activas son las de carácter abierto, originadas por esfuerzos distensivos y dentro del conjunto de fracturas del PNG, también las puede haber de muy baja permeabilidad, por ser de esfuer- 
zos compresivos, por la presencia de materiales alterados que sellen la fractura, o bien por precipitaciones de minerales que rellenen los espacios entre planos de fracturación.

Tanto los granitos como las rocas metamórficas se encuentran cortados por diques (Fig. 5c) y filones, tal como se refleja en la imagen 7 de la figura 4. Más que un tipo de acuífero, estos diques pueden considerarse como estructuras que favorecen la presencia de descargas naturales ya sea porque el dique es de un material más permeable que la roca de caja, ya sea a la inversa: que haga el papel de una pantalla impermeable que fuerce a la descarga del acuífero en forma de manantiales. En cualquiera de los dos casos, la ubicación de un pozo en el contacto dique roca de caja, es un criterio para aumentar las probabilidades de éxito en una captación de aguas subterráneas.

La figura 4 muestra otros dos tipos de acuíferos: el de la imagen 8 consistente en la circulación de aguas a través de los planos de esquistosidad que, evidentemente, solo tiene posibilidad de acontecer en rocas metamórficas, y la imagen 9 en la que se plantea la existencia de manantiales en el contacto entre granitos de distinto tamaño de cristales. Dentro del conjunto de rocas plutónicas, los leucogranitos suelen aparecer más fracturados a causa de los procesos de intrusión y rápido enfriamiento, lo que puede dar lugar a una relativa mayor permeabilidad general del conjunto respecto al resto de granitos. Estos cambios de permeabilidad pueden explicar la aparición de manantiales en las zonas de contacto entre distintos tipos de granitos (Mejías et al., 2015).

No incluido en la figura, pero si indicado en el texto de donde procede, también se consideran los acuíferos formados por alteración superficial sobre rocas metamórficas: la meteorización superficial da lugar a una generalmente delgada capa de alteración donde la porosidad es más elevada que en la roca sana. Esta capa de alteración puede tener importancia local en las zonas en que presenta mayor espesor, pues retrasa el agua de escorrentía y favorece la existencia de pequeños manantiales (ibídem, 2015)

Además de los ya comentados, existen otros tipos de depósitos recientes con capacidad de dar lugar a pequeños acuíferos libres como los conos de deyección originados en la salida de los barrancos, formados por bloques y cantos con matriz arenosa, que pueden dar lugar a rezumes y pequeños manantiales en su extremo inferior al contacto con las hard rocks; análogo comportamiento hidrogeológico suponen los glacis de vertiente de granulometría más fina y los depósitos de fondos de navas con limos y arenas, y en cierto casos las turberas (Fig. $5 \mathrm{~d}$ ). A primera vista las turberas tienden a relacionarse con los acuíferos, pero realmente se trata de una acumulación de materia orgánica con gran capacidad de absorción de agua que después drena lentamente; las turberas cumplen un papel regulador como los acuíferos, pero no es igual su funcionamiento hidrológico.

Además de las aguas de circulación profunda a las que se refiere el siguiente apartado, cabe la posibilidad, puntual, que se den zonas de alteración con espesores de decenas de metros que permitan una mayor penetración de las aguas en el subsuelo, en comparación con los pocos metros de los acuíferos anteriores. Argumentos a favor son el inventario en la Sierra de Guadarrama de un pozo perforado de medio centenar de metros sobre granito capaz de mantener un caudal continuo de uno a dos de litros por segundo (Yélamos, 1991), el manantial del Collado en el término de Bustarviejo, con un continuo de $1.5 \mathrm{~L} / \mathrm{s}$ y un pozo de $50 \mathrm{~m}$ junto a este, capaz de suministrar entre 4 y $5 \mathrm{~L} / \mathrm{s}$ sin guardanivel (Yélamos, 1997).

La confirmación de la existencia de tales espesores de lehm granítico ha venido de los resultados de los sondeos de investigación para un proyecto de sincrotrón en el municipio de El Escorial realizados por el SGOP (1969). En el corte hidrogeológico de la figura 6 puede apreciarse como en el sondeo S15 se atraviesan $20 \mathrm{~m}$ de arenas antes de cortarse el granito sano, mientras que en el S4 se llegó hasta $35 \mathrm{~m}$ sin alcanzar la roca madre. Para los restantes 18 sondeos de investigación, la zona de arena o de granito alterado no sobrepasó los $10 \mathrm{~m}$ de profundidad, apoyando la idea de que estos dos sondeos, que además estaban próximos, debieron cortar una fractura por donde la circulación de aguas subterráneas favoreció la arenización del granito y a la aparición de un acuífero local profundo por porosidad intergranular.

\section{Las aguas de circulación profunda}

Dejando claro que la mayor parte del flujo subterráneo tiene lugar en los acuíferos someros que se han descrito en las páginas anteriores, hay un par de evidencias que llevan a plantear la existencia de un flujo profundo a través de las discontinuidades presentes en el conjunto del macizo rocoso, pero de muy bajo caudal.

La primera es la aparición de tres sondeos surgentes en las cotas más bajas del arroyo de Aguilón. Estos formaban parte de los trabajos previos en el túnel del TAV en los cuales los restantes sondeos situados sobre hard rocks siempre marcaban un nivel de agua a escasa profundidad de la superficie.

Para justificar estos sondeos surgentes cabe suponer un modelo conceptual de flujo basado en las ideas propuestas por Toth $(1962,1963)$ para las pequeñas 


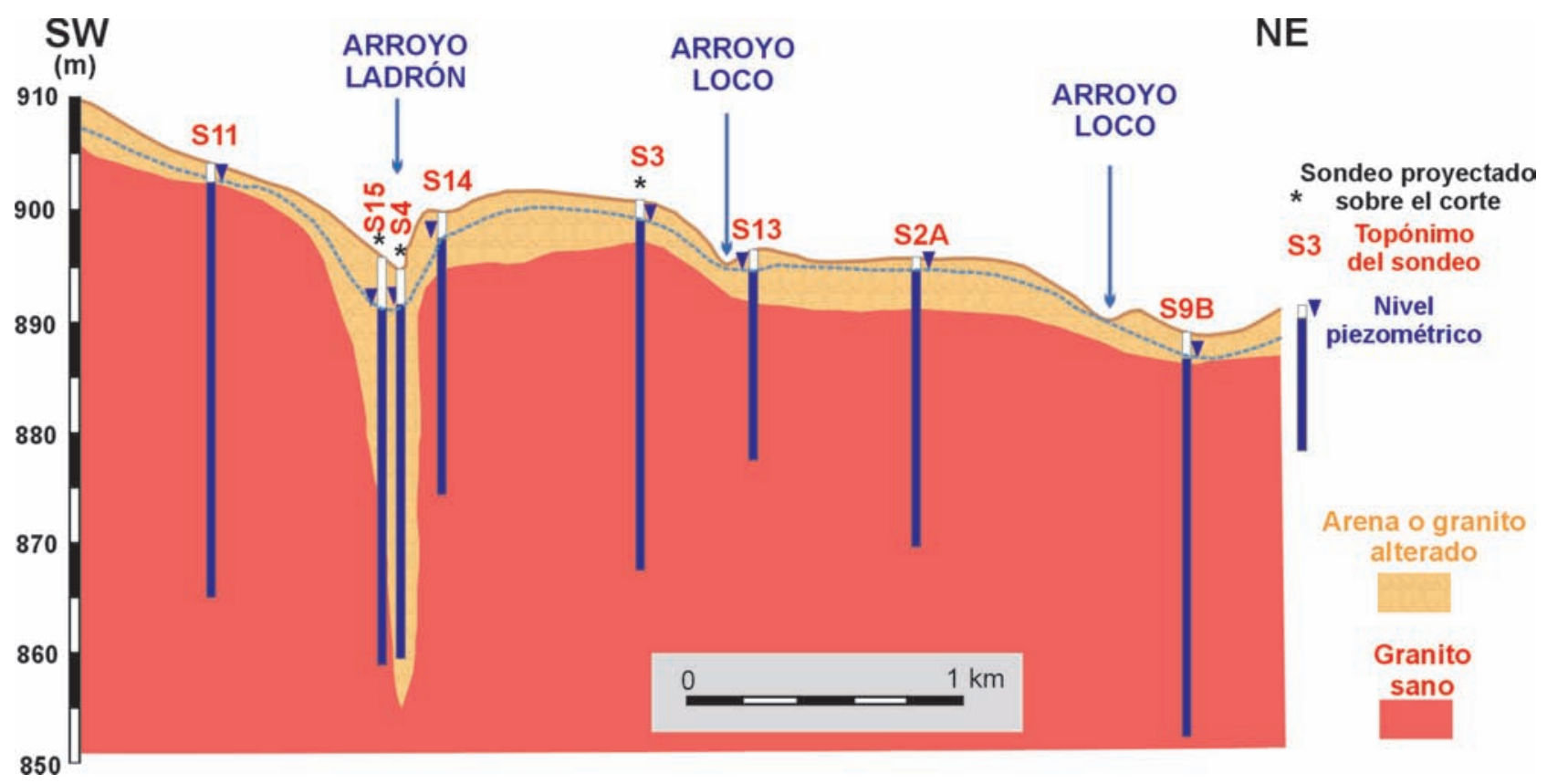

Figura 6. Perfil hidrogeológico a partir de los sondeos para un proyecto de sincrotrón (Yélamos, 1991).

Figure 6. Hydrogeological cross-section based on data from the boreholes of a synchrotron project (Yélamos, 1991).

cuencas sedimentarias de Canadá. Al conjunto de rocas metamórficas y plutónicas se le considera como una unidad hidrogeológica individual, en la que las discontinuidades que afectan al macizo rocoso permiten una escasa y lenta, pero profunda, circulación de agua. Además, aparecerían tres tipos de flujos: a) locales, que podrían ser los responsables de descargas en pequeños manantiales, b) intermedios, que justificarían el carácter surgente de los sondeos cercanos al cauce del arroyo Aguilón y c) regionales, que descargarían en los puntos más bajos del macizo de rocas plutónicas y metamórficas; estos también podrían alimentar al acuífero formado por las rocas sedimentarias de las vecinas cuencas delTajo y del Duero, si bien su influencia sería despreciable dado los bajos recursos de las hard rocks en comparación con los acuíferos presentes en ambas cuencas sedimentarias.

El límite superior de esta "unidad acuífera" estaría definida por el nivel de agua en los sondeos que captan los acuíferos someros, de manera que su nivel freático vendría a ser una reproducción suavizada de la fuerte topografía de la zona. La figura 7 muestra este posible modelo conceptual de flujo con el que se justifica la surgencia de los sondeos y es coherente con los niveles de agua de otros sondeos situados en las laderas.

Un modelo análogo ya fue propuesto para la zona de estudio del proyecto Berrocal (Guimerá et al., 1993), sobre los granitos de la vecina Sierra de Gredos, también perteneciente al Sistema Central.
En principio para justificar la surgencia de un sondeo no hace falta recurrir al modelo de Toth. Sería suficiente con un modelo más simple: disponer de dos fracturas en forma de $\mathrm{V}$; la izquierda con una cota más alta y siendo un área de recarga y la derecha siendo el punto de descarga. Si el material fracturado es impermeable se dispondría de una especie de tubería, de manera que un sondeo en la rama derecha estaría en carga y si la cota topográfica está por debajo del nivel piezométrico, aparecería un sondeo surgente. Sin embargo, hay otra argumentación a favor de la circulación profunda. La facies hidroquímica de los sondeos surgentes es totalmente diferente a la de las aguas de circulación somera. Son aguas evolucionadas, claramente con un mayor tiempo de permanencia en el subsuelo. Desafortunadamente no se dispone de dataciones, de manera que se califican simplemente como aguas más antiguas, de mayor tiempo de permanencia circulando por el conjunto de discontinuidades s.l. que atraviesan el sustrato plutónico-metamórfico. Esta temática se desarrolla más adelante en el apartado dedicado a la hidroquímica de las aguas subterráneas del PNG.

\section{Parámetros hidrogeológicos}

La obtención de valores de parámetros hidrogeológicos en hard rocks es una tarea compleja. Las meto- 


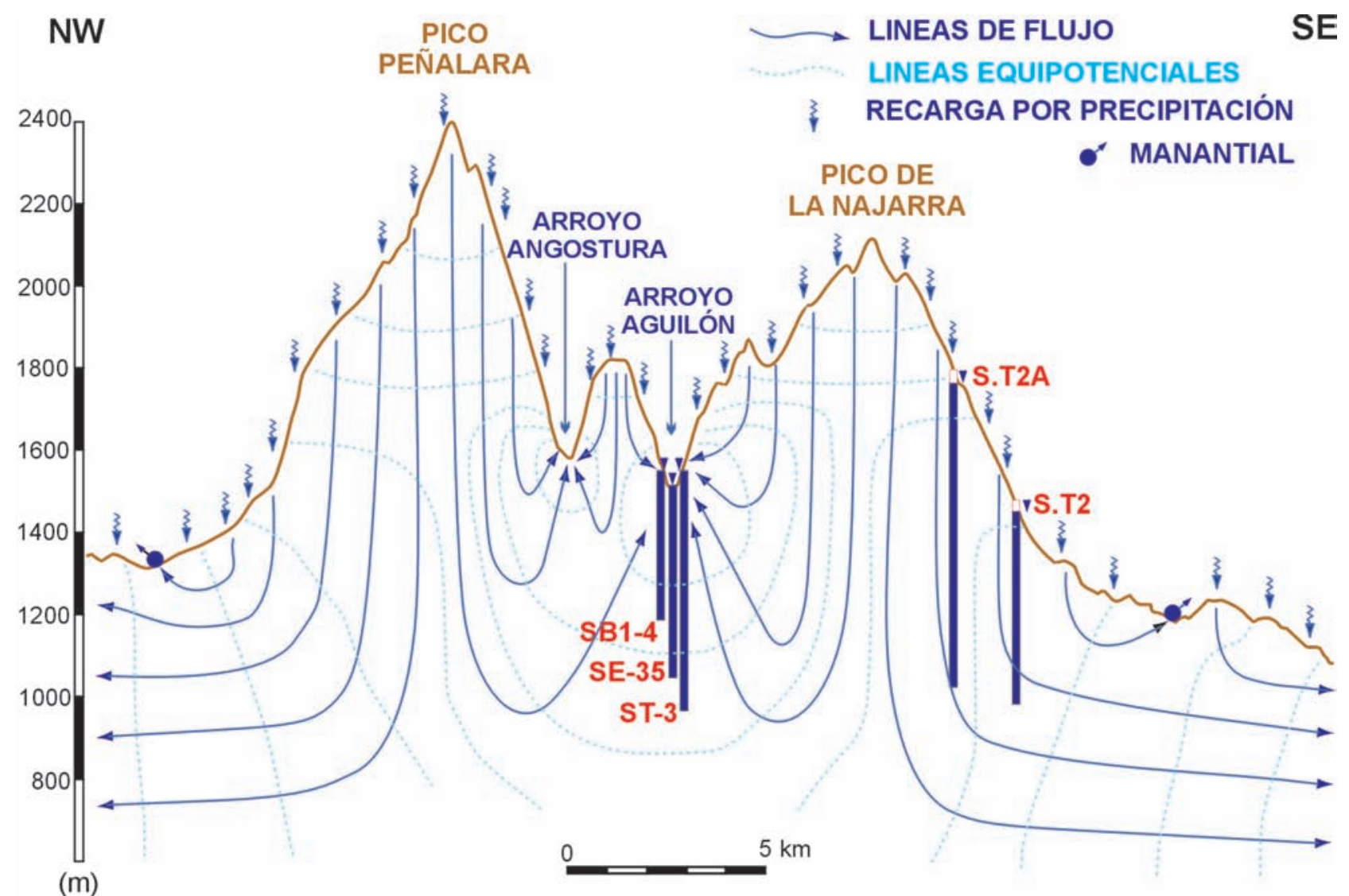

Figura 7. Corte hidrogeológico mostrando el modelo conceptual de flujo profundo para las hard rocks del PNG. Los sondeos SB1-4, SE-35 y ST3 fueron surgentes. Los sondeos están proyectados sobre el perfil topográfico, de manera que la escala de altitudes es solo orientativa (Villarroya et al., 2006).

Figure 7. Hydrogeological cross-section showing the conceptual flow model in the hard rocks of PNG. SB1-4, SE-35 y ST3 were flowing wells. Boreholes are projected over the topographical profile, so the altitude scale is approximate (Villarroya et al., 2006).

dologías estándar de ensayos de bombeo no suelen resultar de utilidad ya que los bajos recursos impiden mantener un caudal constante durante las pruebas. La mayor parte de los pozos en la sierra de Guadarrama, sobre todo los excavados, cumplen una doble función, captación y depósito de agua; de esta manera, un ensayo de bombeo lo que tiende a reflejar es el vaciado de la captación en vez del comportamiento hidráulico de la roca en las que se emplaza.

Sin embargo, a partir de los estudios previos del túnel del TAV sí que se ha obtenido información sobre los parámetros hidrogeológicos de las rocas de la Sierra de Guadarrama. Durante los trabajos previos se realizaron tres conjuntos de pruebas de inyección tipo Lugeon: 1) La alternativa Torre 2) la alternativa Centro y 3 ) algunas pruebas iniciales realizadas por RENFE.

Los resultados de todas estas pruebas aparecen representados en el gráfico de la figura 8.

La primera observación es que no se aprecia nin- guna correspondencia clara entre los valores de permeabilidad y la profundidad del ensayo. Esto no invalida lo indicado anteriormente en relación a la zona más permeable dentro de los acuíferos someros, ya que los ensayos Lugeon solo se realizaron a profundidades superiores a $20 \mathrm{~m}$.

Si se consideran solo los ensayos realizados por RENFE sí que es posible apreciar una cierta correlación negativa entre la permeabilidad y la profundidad. Al añadir los datos de la alternativa La Torre se incrementa el rango de valores de permeabilidad y no se aprecia relación con la profundidad. Quizás esto sea debido a un efecto de escalado: los valores de permeabilidad se incrementan al aumentar la escala de la medida e igualmente surge una mayor dispersión de valores.

Por otro lado, los valores obtenidos en la alternativa Centro tienen un margen de variación muy limitado, $\tan$ solo entre $10^{-8}$ y $10^{-9} \mathrm{~m} / \mathrm{s}$ sin ninguna correlación con la profundidad. 


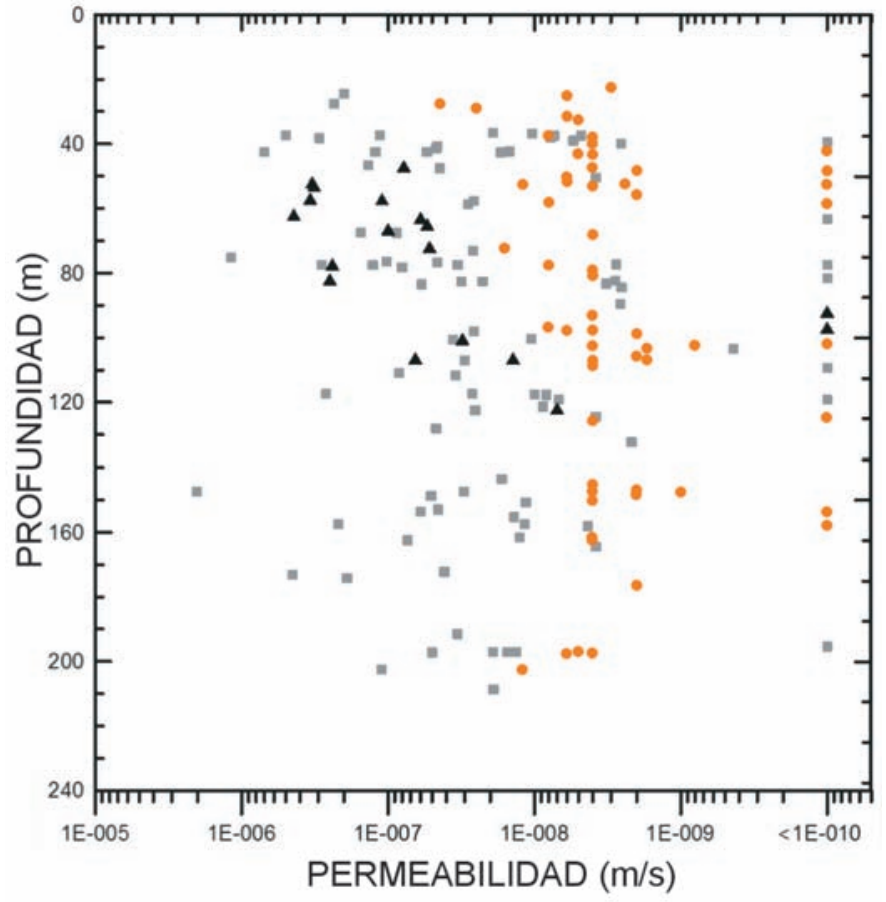

Figura 8. Representación de los valores de permeabilidad frente a la profundidad. a) Los cuadrados grises son los valores de la alternativa Torre. b) Círculos naranjas la alternativa Centro. c) Los triángulos rojos indican los valores de los sondeos de RENFE. Como la escala es logarítmica, los valores de absorción nula se han representado sobre la línea de permeabilidad >1E-010 (Villarroya et al., 2006).

Figure 8. Plot of permeability data versus depth. a) Grey squares represent Torre alternative values. b) Orange circles, Centro alternative. c) Red triangles show data in RENFE boreholes. As the scale is logarithmic, zero water absortion is plotted over the line of permeability <1E-010 (Villarroya et al., 2006).

Además de los ensayos de inyección, se realizaron cinco ensayos de bombeo con caudales de tan solo 0.12 a $0.15 \mathrm{~L} / \mathrm{s}$. Los ensayos se interpretaron por el método de Jacob tanto en descenso como en recuperación y los valores de transmisividad obtenidos oscilaban entre los 0.038 y $0.2 \mathrm{~m}^{2} /$ día.

Con tan bajos valores de permeabilidad la perforación del túnel no presentó ningún problema de carácter hidrogeológico. En los 3 o $4 \mathrm{~km}$ primeros desde la boca sur, y según el Dr. Ing. Luis Pinillos, ingeniero que estuvo en la construcción, no hubo a apenas flujos importantes de agua. A veces salían como mucho unos $10-15 \mathrm{~L} / \mathrm{s}$ de manera repentina pero que prácticamente se agotaban en menos de un día. Estos flujos estaban asociados a zonas meteorizadas, sobre todo relacionadas con fracturas, a veces secundarias y cuando pasaban por vaguadas o valles, es decir, con poca cobertera.

Finalmente, no conviene dar un especial valor a los valores presentados de parámetros hidráulicos. En primer lugar, los ensayos Lugeon fueron realizados en sondeos pensados más con criterios geotécnicos que no hidrogeológicos. Además, no está claro que el método de Jacob, desarrollado para acuíferos con porosidad intergranular, sea aplicable los acuíferos por fracturación. Simplemente, estos datos confirman la muy baja permebilidad y transmisividad del macizo rocoso en el que se ubica el PNG.

\section{El acuífero sedimentario del Alto Valle del Lozoya}

Los sedimentos de la cuenca del Alto Valle del Lozoya son un contexto hidrogeológico totalmente diferente al de las hard rocks, con manantiales y pozos capaces de aportar caudales de varios litros por segundo e incluso decenas. Se trata de un acuífero que, tal vez por su escasa extensión, no aparece señalado en las cartografías realizadas por los distintos organismos encargados de la gestión las masas de agua subterránea, pero es una entidad claramente diferenciable del resto de las litologías que la rodean.

De forma más o menos explícita, sus calizas ya estaban incluidas en el inicial sistema acuífero 17 Reborde Mesozoico del Guadarrama (ITGE, 1989), pero no aparecen marcadas en la cartografía $y$, menos aún, en el primer mapa a pequeña escala de unidades hidrogeológicas, como parte de la unidad hidrogeológica 03.03 Torrelaguna Jadraque (SGOPITGE, 1990); tampoco están explícitamente señaladas dentro de la, hoy en día, conocida como masa de agua 030.004 Torrelaguna (CHT, 2015). En cambio, sí que aparece cartografiadas en los distintos mapas hidrogeológicos realizadas por el IGME a escalas más detalladas (IGME, 1981a; ITGE, 1988).

A falta de estudios más detallados, el acuífero es en principio de naturaleza libre, formado principalmente por calizas del Cretácico que han sufrido karstificación. Sobre estas calizas aparecen materiales detríticos paleógenos y un recubrimiento de coluviones y terrazas que también tienen naturaleza de acuíferos, pero en este caso por porosidad intergranular; de ahí el que se haya optado por definirlo como acuífero sedimentario en vez de como solo kárstico.

Su recarga acontece por dos vías: 1) la infiltración de las precipitaciones sobre los aproximadamente 40 $\mathrm{km}^{2}$ de afloramientos sobre los que se extienden los sedimentos y 2) la recarga por los arroyos que cruzan las calizas hasta desembocar en el río Lozoya, siendo previsible, sobre todos en el verano, que tengan un carácter de cursos de agua perdedores (Fig. 9). A partir de la realización del embalse de Pinilla (1967), este puede ser una tercera fuente de recarga, o bien de 


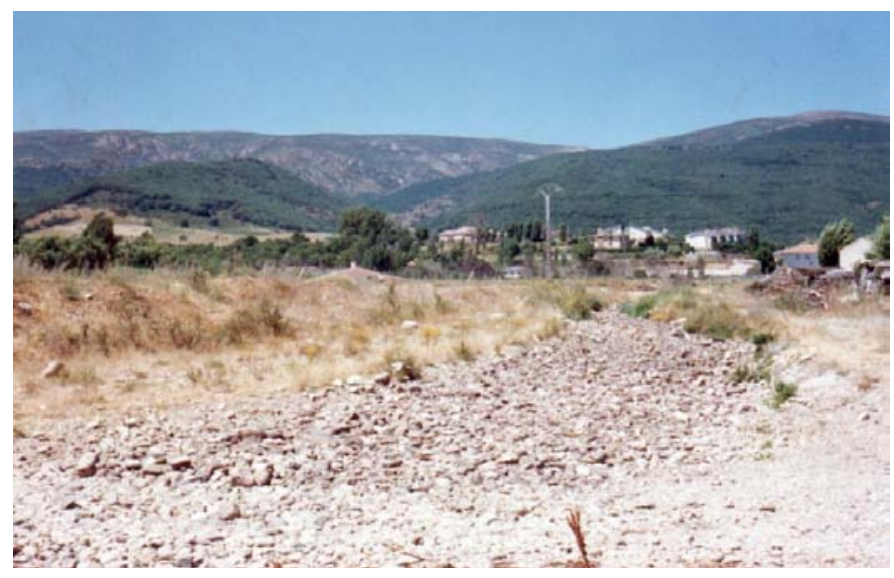

Figura 9. Arroyo Artiñuelo, verano de 1988; disponía de agua al circular sobre los gneises de las montañas del fondo, pero se iba filtrando a medida que se desplazaba sobre el acuífero sedimentario del AVL hasta quedar seco tal como se aprecia en la fotografía.

Figure 9. Artiñuelo creek, summer of 1988; it had water flowing over the gneisses of the mountains in the background, but it was infiltrated into the sedimentary aquifer of the AVL until it became dry as seen in the photograph.

descarga, dependiendo de su cota de agua. Esta posibilidad se confirmó a modo de prueba de trazado accidental durante el verano de 1981; con el nivel del embalse a baja cota y agua eutrofizada, al bombearse un pozo perforado de abastecimiento a Lozoya empezó a salir agua de color verde y mal olor (Yélamos, 1986).

La descarga tiene lugar de forma natural hacia el cauce del río Lozoya, pero también acontece a partir de manantiales de naturaleza kárstica, siendo los dos más importantes los de Batanes y Molinos (Fig.10) con caudales que pueden alcanzar los 20 L/s (SGOP, 1982). Obviamente también hay una descarga a partir de los pozos de la zona, tanto para abastecimiento municipal como para particulares.

López Vera (1985) estima para este acuífero sedimentario un volumen almacenado de $38 \mathrm{hm}^{3}$ y unos recursos subterráneos de $3.7 \mathrm{hm}^{3} / a n ̃ o$. Curiosamente la primera cifra coincide con la capacidad del embalse de Pinilla, que como ya se ha indicado, tiene conexión hidráulica con el sector oriental del acuífero.

En relación a los parámetros hidrogeológicos, por comparación con las vecinas calizas de la unidad Torrelaguna estudiadas en detalle por Corchón (1976), se pueden esperar altas permeabilidades entre $10 \mathrm{y}$ $20 \mathrm{~m} /$ día pero que pueden bajar en dos órdenes de magnitud en las zonas menos karstificadas, y una porosidad eficaz comprendida entre un 2 y un 5 por cien. En los sondeos de investigación del TAV se realizaron ensayos Lugeon para el conjunto de sedimentos cretácicos (areniscas, limos, lutitas y calizas), no

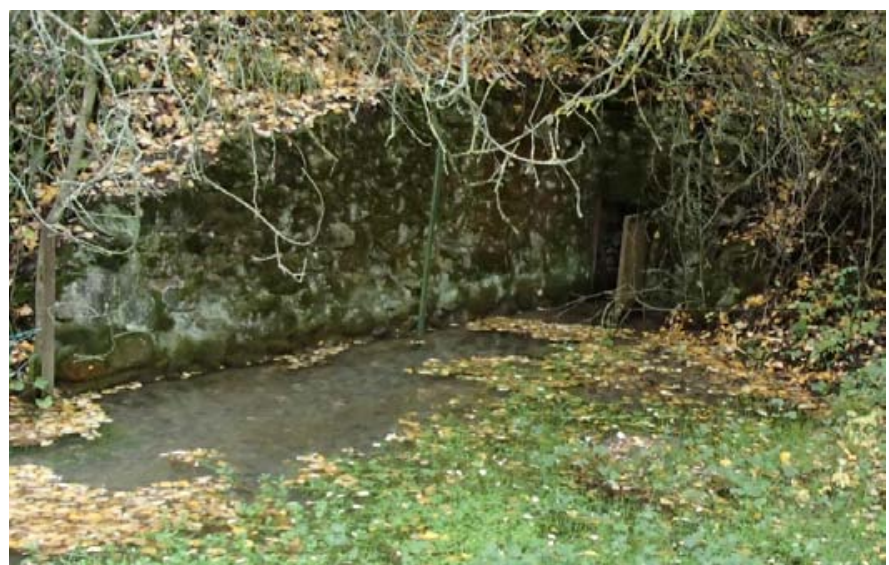

Figura10. Manantial kárstico de la Fuente de los Batanes (Rascafría), punto de nacimiento de un cauce fluvial que tras recorrer unas decenas de metros desemboca en el rio Lozoya.

Figure 10. Karstic spring of the Batanes fountain (Rascafria), birthplace of a river course flowing tens of metres before its discharges into the Lozoya River.

solo las calizas, obteniéndose unas permeabilidades muy bajas, de tan solo $0.001 \mathrm{~m} /$ día (GIF, 2001).

\section{Calidad química de las aguas subterráneas}

La calidad química natural de las aguas subterráneas es el resultado de la suma de cuatro factores: 1) la solubilidad de los minerales en las rocas que forman el acuífero, 2) el tiempo de permanencia del agua en contacto con ésta, 3) el clima y 4) relacionado con este factor y el primero, el tipo de suelo que tienen que atravesar las aguas de infiltración antes de alcanzar el límite superior de la zona saturada. En el caso de las rocas plutónicas y metamórficas del PNG estos cuatro factores convergen para dar lugar a que se trate de aguas de muy baja salinidad y $\mathrm{pH}$ ácido.

Los minerales son tecto o filosilicatos poco solubles, en los que la acción del agua de lluvia se limita a una disolución incongruente que aporta sílice y cationes en disolución, principalmente el calcio de las plagioclasas más solubles. El tiempo de permanencia en el subsuelo en caso de los acuíferos someros es corto. El clima frío impide o disminuye tanto los procesos de concentración de sales por evapotranspiración, como la acción de microorganismos en el suelo que catalicen los procesos de generación de ácido carbónico.

El mapa hidrogeoquímico de la figura 11, en base a los datos de GIF (2001), muestra como la mayor parte de las aguas presentes son de facies hidroquí- 


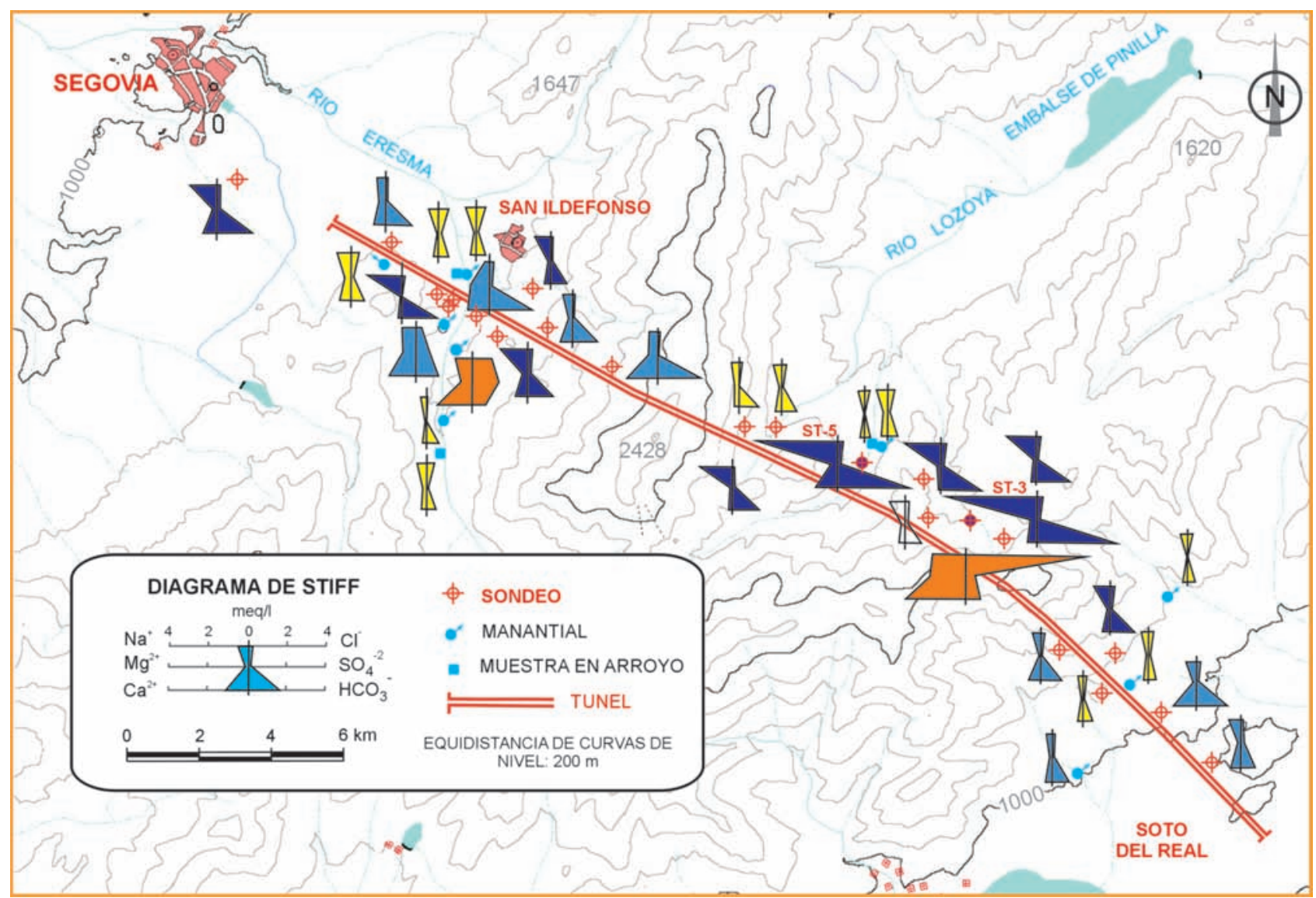

Figura 11. Mapa hidrogeoquimico de los alrededores del túnel para el tren de alta velocidad. Modificado de Villarroya et al., 2006. Figure 11. Hydrogeochemical map of the surrounding area of the high velocity train tunnel. Modified from Villarroya et al., 2006.

mica bicarbonatada cálcica o bicarbonatada-clorurada cálcico-sódica. Estas segundas son de muy baja salinidad y $\mathrm{pH}$ ácido, de manera que muy posiblemente los únicos procesos que les aportan sales son la evaporación del agua de las precipitaciones y una leve disolución de silicatos; cuando este proceso gana intensidad, es cuando cabe esperar las aguas de facies claramente bicarbonatada cálcica y pH más básico.

Hay una tercera facies hidroquímica que cobra un especial interés y que es precisamente la que aparece en los sondeos surgentes; estas aguas se diferencian de las anteriores en: a) mayor salinidad, b) una marcada facies bicarbonatada sódica, c) pH básico de 7 a 8.9 y d) una elevada concentración de flúor, entre 5.5 y $12 \mathrm{mg} / \mathrm{L}$.

Todo ello indica unas aguas de circulación profunda, en la que a medida que circulan por el complejo ígneo-metamórfico sufren procesos de pérdida del catión calcio y su sustitución por el de sodio a la vez que se incrementa el pH por la disolución de plagioclasas sódicas.
Similar facies hidroquímica, bicarbonatada sódica con pH claramente básico, es la que aparece en las aguas minerales sulfurosas que se describen en el último capítulo, a las cuales también cabe interpretarlas como aguas de circulación profunda por el conjunto de discontinuidades del macizo plutónico-metamórfico.

En relación a la calidad química del acuífero sedimentario del Alto Valle del Lozoya, sus aguas también presentan una facies bicarbonatada cálcica que se diferencia de la de las hard rocks someras al tener unos más altos valores de salinidad, por encima de los $150 \mathrm{mg} / \mathrm{L}$ de total de sólidos en disolución. En este caso, el origen de los dos iones mayoritarios se debe a la disolución natural de los minerales carbonatados presentes en las calizas, proceso que se ve favorecido por la mayor producción de dióxido de carbono en los suelos mejor desarrollados sobre los aluviales del Lozoya que en las pendientes de la Sierra.

Los posibles focos de contaminación que puedan alterar la calidad de las aguas subterráneas en lo que es el PNG son prácticamente nulos al tratarse de una 
zona sin actividad antrópica importante salvo las actividades de ocio. Quizás la única posibilidad a comentar sea el uso de sales en las carreteras de montaña con el objetivo de favorecer la fusión de la nieve. Dicha actividad podría alterar puntualmente la calidad natural de las aguas tanto superficiales como subterráneas con incrementos puntuales de los iones que se aportan al terreno, pero sin esperar grandes alteraciones. Analizando un periodo de cinco años en la estación 172 de la red COCA sita en el río Lozoya a la altura de Alameda del Valle, Caballero (2013) encuentra un par de inviernos con picos de 12 y 25 $\mathrm{mg} / \mathrm{L}$ de cloruros frente a un valor de fondo a lo largo de todo el año entre 5 y $10 \mathrm{mg} / \mathrm{L}$.

Similar comentario se puede hacer sobre el uso de productos químicos en la estación de invierno de Valdesquí cuando recurren a la nieve artificial.

El mayor riesgo de degradación de la calidad del agua subterránea acontece sobre el acuífero sedimentario del AVL ya que sobre su superficie se asientan cinco núcleos de población más una urbanización, cuyas fugas en el sistema de alcantarillado son una fuente potencial de afección al acuífero; pero precisamente esos cascos urbanos, donde otros posibles focos de contaminación serían el par de estaciones de servicio existentes, no pertenecen sensu stricto a la banda de protección del parque. Antaño existieron un par de pequeños vertederos de residuos sólidos urbanos sobre el acuífero, para dar servicio a las localidades de Rascafría y Lozoya (IGME, 1981b) pero llevan décadas clausurados.

\section{Hidrogeología del Parque Natural de la Cumbre, Circo y Lagunas de Peñalara}

\section{Introducción}

EI PNG ha incorporado en su territorio otras áreas protegidas anteriores como es el caso del Parque Natural de la Cumbre, Circo y Lagunas de Peñalara (en adelante PNP), declarado como tal por la Comunidad de Madrid en 1990 y ocupando poco más de 750 ha de la provincia madrileña.

Se trata de un área de especial importancia ecológica y paisajística dentro del PNG de manera que se ha realizado un estudio más en detalle de su hidrogeología. Evidentemente al estar en una zona de cumbre, alejada de núcleos de población y demandas de agua, los únicos puntos de agua existentes son los manantiales, no hay captaciones de aguas subterráneas a partir de pozos perforados o excavados. También hay arroyos ganadores donde se verifica una descarga difusa, y este el motivo por el que se hicieron aforos diferenciales en los cauces de la red de drenaje, a fin de identificar tramos efluentes. En el trabajo original (Sanz Pérez, 1998), se perseguía localizar fracturas permeables en los tramos rectilíneos efluentes ajustados a fallas y que pudieran dar problemas de entradas de agua durante la excavación del túnel de Guadarrama. Especial cuidado se tuvo en analizar las fracturas que atraviesan el territorio de las lagunas y zonas húmedas del Macizo de Peñalara, y que podría eventualmente vaciarlas en mayor o menor medida. Sin embargo, se pudo comprobar que la mayor parte de las descargas provenían de la zona de alteración y formaciones superficiales y, como se pudo constatar después, la perforación del túnel no supuso ninguna afección a las lagunas.

La presencia de estos manantiales en el Parque Natural está claramente relacionada con las formaciones superficiales de la zona, siendo el área del Parque donde se da la mayor concentración de formas de origen glaciar y periglaciar de la Comunidad de Madrid. Por este motivo, en el siguiente apartado se incluye una descripción en detalle de las existentes.

\section{Formaciones superficiales y de alteración en el Macizo de Peñalara}

El Macizo de Peñalara corresponde al sector de máxima altitud de la Sierra del Guadarrama (2429 m, Pico de Peñalara). Está formado por un sustrato de ortogneis con numerosas intrusiones aplíticas y graníticas que se halla parcialmente recubierto por mantos de alteración y por depósitos de origen glaciar o periglaciar que han sido estudiados en las últimas décadas por Sanz Herráiz (1988), Acaso et al. (1998) y Palacios y Andrés de Pablo $(2000,2005)$. Estas formaciones superficiales, ya sean heredadas o actuales, no se distribuyen exactamente en pisos altitudinales, sino que se reparten según la orientación de las vertientes respecto de los vientos dominantes, que han influido grandemente en la desigual acumulación de la nieve en la montaña.

Así, y según Palacios y Andrés de Pablo (2000, 2005), en la vertiente oriental del PNP, aparecen voluminosas morrenas glaciares pleistocenas y morrenas de nevé. En las vertientes suroccidentales, la segoviana del PNG, apenas existen formas glaciares y la ladera se halla cubierta por un manto de alteración heredado, bien desarrollado y bastante continuo, de $1.5 \mathrm{~m}$ de espesor medio. La vertiente noroccidental de Peñalara aparece cubierta de forma generalizada por un campo de bloques periglaciares, seguramente coetáneo con los glaciares pleistocenos de la vertiente oriental (Fig.12). 


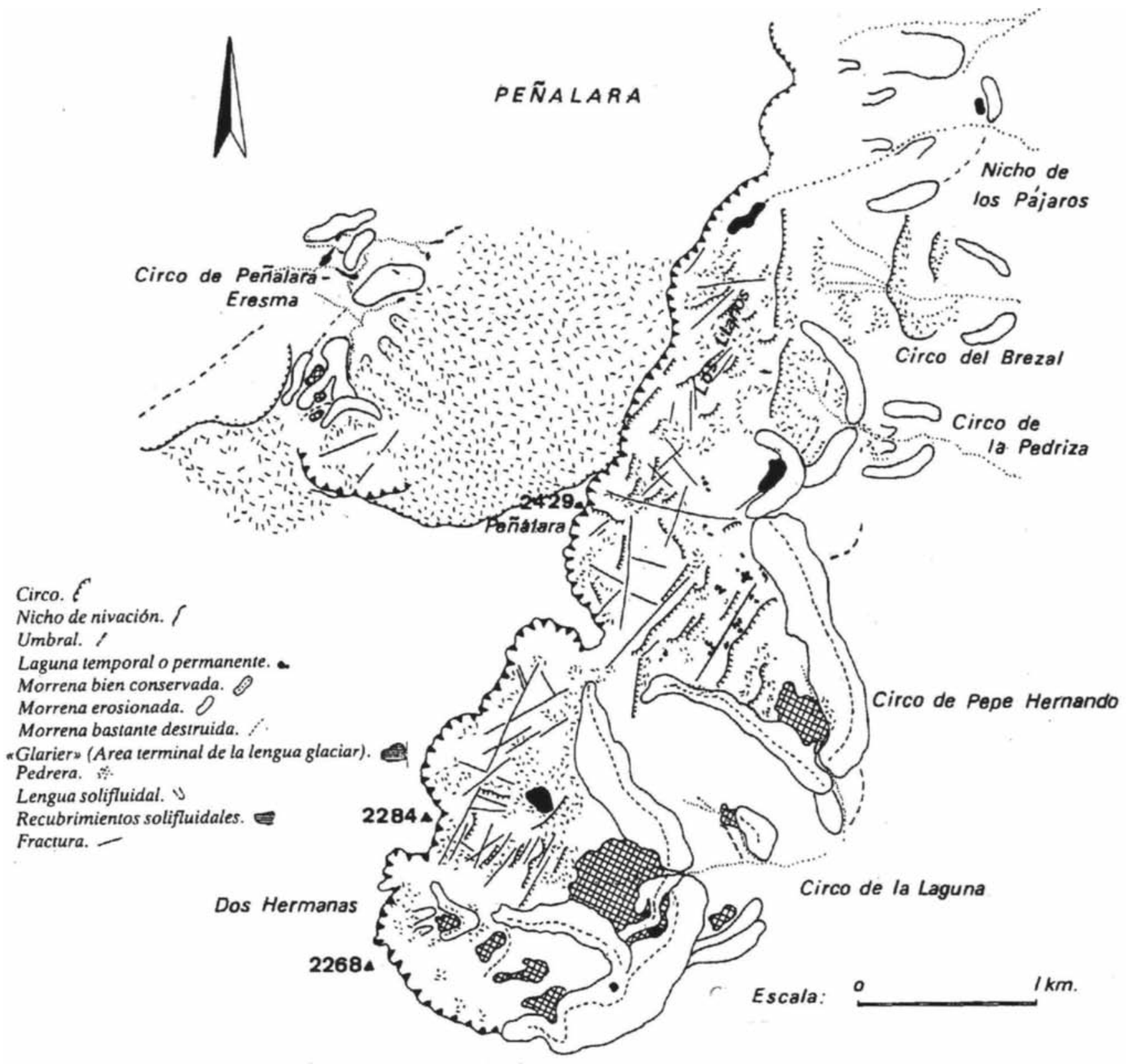

Figura 12. Formaciones glaciares y periglaciares del Macizo de Peñalara (Sanz Herráiz, 1988).

Figure 12. Glacial and periglacial formations of Peñalara Massif (Sanz Herráiz, 1988).

En concreto, y desde el punto de vista hidrogeológico, en las áreas de altura podemos encontrarnos las siguientes formaciones superficiales y de alteración (Palacios y Andrés de Pablo, 2000, 2005) que pueden constituir pequeños acuíferos:

1) Mantos de alteración y depósitos de origen complejo, que cubren los llanos de las cumbres y laderas, donde los gneis glandulares, granitos y aplitas están alteradas hasta una profundidad de 4-5 m. Forman un saprolito arenoso de cuarzo y feldes- pato, principalmente, aunque conserva núcleos de roca fresca; se desconoce cómo y cuándo se formó, aunque se cree está asociado al último interglaciar. No constituye un manto continuo, si no que ha sido desmantelado allí donde la acción erosiva de los glaciares de la última glaciación han barrido esta capa, haciendo aflorar el sustrato rocoso.

2) Campos de bloques periglaciares que se depositan a veces encima de este manto de alteración. En la 
vertiente noroccidental, los campos están ordenados en lóbulos más o menos alargados según la pendiente de la ladera en longitudes de entre 10$50 \mathrm{~m}$ y anchuras entre 5-30 $\mathrm{m}$. En el interior de estos lóbulos predominan los bloques pequeños, cantos y finos; en el anillo exterior se disponen los grandes bloques sin matriz fina, de entre 1-1.5 m, y con diámetro máximo de $3 \mathrm{~m}$. También hay una estratificación según la profundidad, donde los bloques de arriba están más lavados, habiéndose arrastrado los finos en profundidad.

3) Formaciones morrénicas de los glaciares de la última glaciación, que predominan en la vertiente oriental.

4) Formaciones postglaciares, entre las que se citan: protalus rampant, lenguas solifluidales y lóbulos de solifluxión, acumulaciones nivo-aluviales y terrazas de nivoplanacion asociada a los nichos de nivación, conos de gravedad, coladas de debris fows y turberas.

\section{Manantiales y caudales de los arroyos del Macizo de Peñalara durante el estiaje de 1989.}

Al realizar el inventario en estiaje, el número de manantiales y sobre todo de rezumes, ha sido sin duda menor que si la campaña hubiese sido tras el deshielo de mayo o junio, con la aparición de multitud de surgencias efímeras. La longitud de los cursos de agua será también mayor tras el deshielo, y los que se reflejan en las figuras 13 y 14 referidas a las vertientes madrileña y segoviana del macizo de Peñalara, tienen un régimen más o menos permanente.

\section{Modelo conceptual de funcionamiento hidrogeológico}

El modelo conceptual de funcionamiento hidrogeológico en las laderas altas de estas montañas pivota principalmente sobre tres puntos:

1. Los acuíferos y acuitardos de baja y media permeabilidad los constituyen los mantos de alteración y formaciones superficiales de origen glaciar, periglaciar y postglaciar, cuyo pequeño espesor hace que el juego hídrico se restringa a no más de los 10 primeros metros superiores.

2. Condicionantes topográficos: precisamente porque son formaciones superficiales y por tanto adaptadas a la geometría de las vaguadas, la topografía controla el flujo subterráneo subsuperficial, de tal manera que los circos de origen glaciar del Parque Natural de Peñalara, de forma cóncava, facilitan la

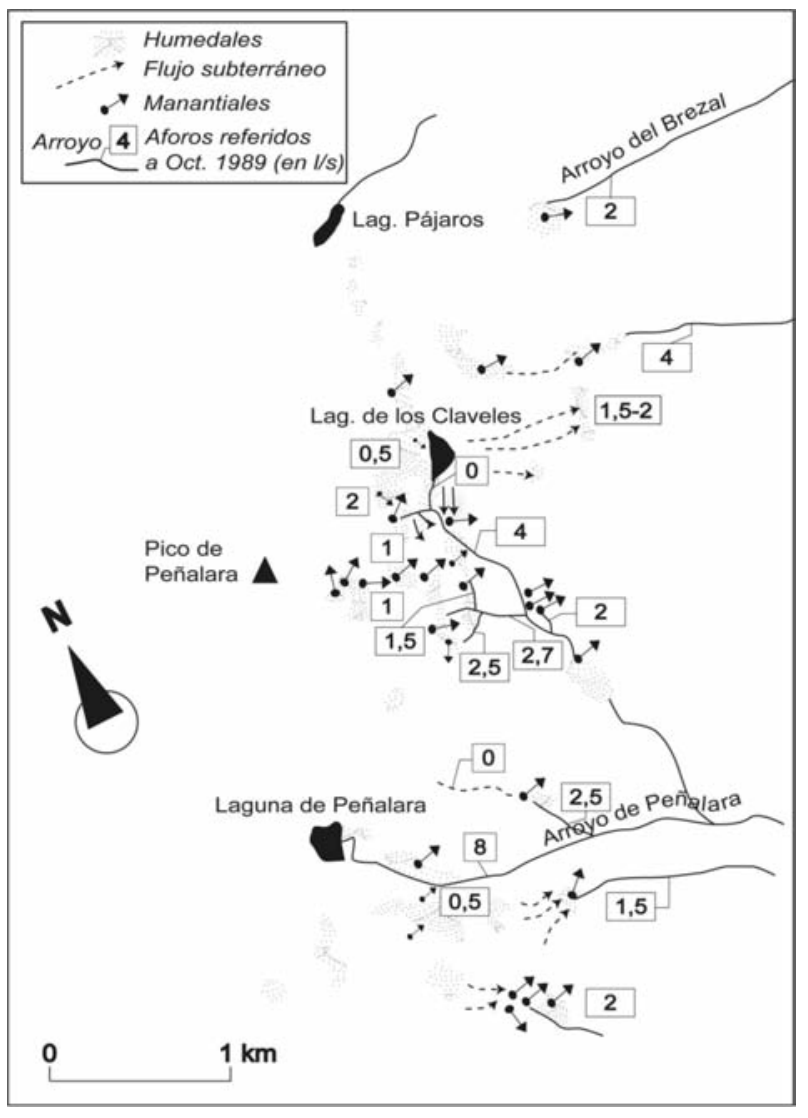

Figura 13. Manantiales y caudales de los arroyos del PNP durante el estiaje de 1989 (Sanz Pérez, 2004).

Figure 13. Springs and flow rates of PNP streams during the dry season of 1989 (Sanz Pérez, 2004).

acumulación de agua y la concentración del flujo subterráneo en su fondo. En la vertiente opuesta del macizo de Peñalara, los flujos locales recorren toda la ladera hasta alcanzar la superficie de menos pendiente de la base, o cuando desaparecen las formaciones superficiales.

3. Recarga de nieve: este tipo de recarga es bastante importante en el Parque Natural de Peñalara. Hay que tener en cuenta que la permanencia de la nieve en el suelo oscila entre menos de 46 días hasta más de 220 días entre 1990 y 1996 (Palacios y Andrés de Pablo, 2000, 2005).

La orientación es el criterio topográfico fundamental que condiciona el reparto de superficie cubierta por la nieve, de tal manera que las laderas orientadas al NE y $\mathrm{N}$ son mayores que las orientadas al SE y O. Al superponer los mapas de duración de la nieve (Palacios y Andrés de Pablo, 2005) con las formaciones superficiales se puede comprobar que la nieve permanece largo tiempo sobre ellas $y$, considerando 


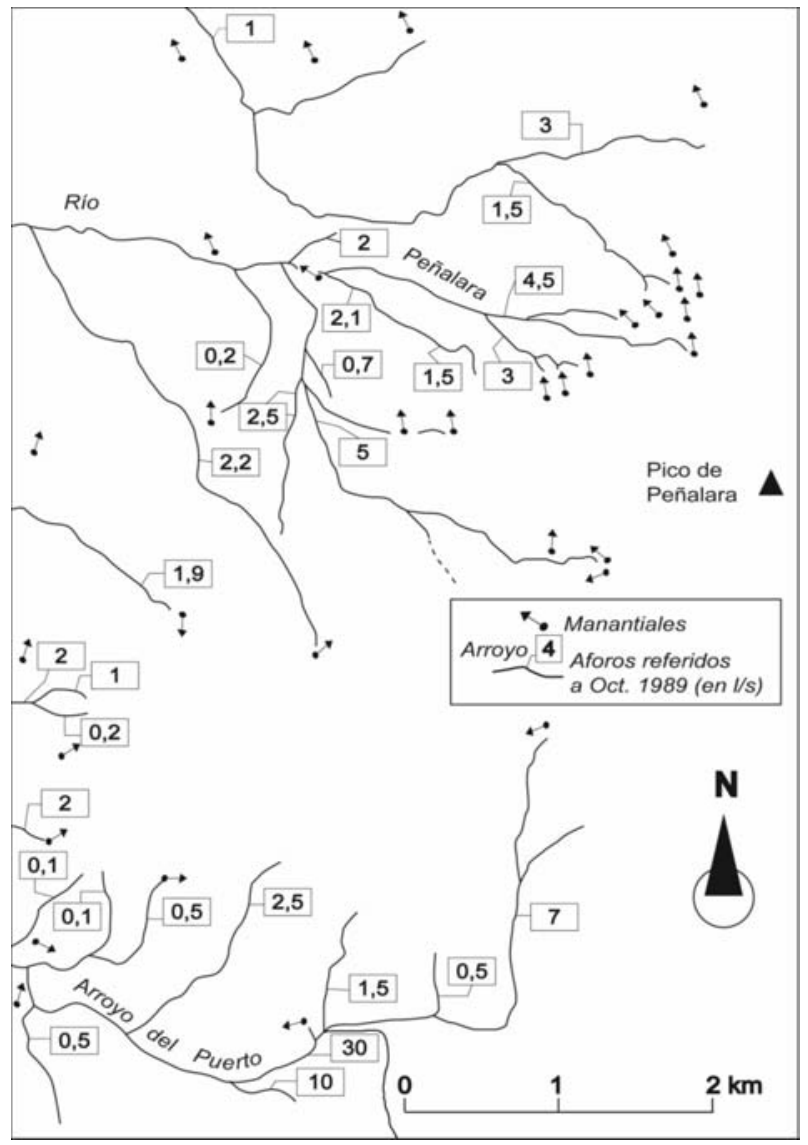

Figura 14. Manantiales y caudales de los arroyos del Macizo de Peñalara durante el estiaje de 1998 en la vertiente occidental (Sanz Pérez, 1998).

Figure 14. Springs and flow rates of streams on the western slopes of the Peñalara Massif during the dry season of 1998 on the western slopes (Sanz Pérez, 1998).

que la permanencia no es continua, sino eventos de nevadas y deshielos, se comprende que la recarga sea importante, y explica la frialdad (hasta de $5-6^{\circ} \mathrm{C}$ ) del agua de varias fuentes.

La nieve constituye un almacén hídrico que retarda y regula la escorrentía superficial y favorece la recarga. Hay que tener en cuenta que la sublimación, aun en montañas tan soleadas como esta, es muy pequeña respecto a la evaporación. Después de una precipitación de lluvia, un charco se puede evaporar al día siguiente si hace calor; sin embargo, si la precipitación ha sido en forma de nieve, esta se derrite y constituye agua útil para que se pueda infiltrar empampado el terreno si este tiene suficiente porosidad y permeabilidad. La nieve hace además de aislante térmico y permite la infiltración de agua líquida durante su fusión durante muchos meses al año, acentuando los procesos de recarga, empapando las capas superficiales del manto de alteración y canchales, permitiendo la existencia de agua líquida en el subsuelo, a diferencia de las áreas no innivadas, más expuestas a las heladas con suelos congelados e impermeables. La fusión de la nieve ocurre en estas montañas sobre todo en abril y mayo (Palacios y Andrés de Pablo, 2005).

La media de total de días al año con nieve en el suelo en Navacerrada es de 82, pero debido al calentamiento global, la temperatura media en los 30 últimos años ha subido casi $2^{\circ} \mathrm{C}$ en primavera, por lo que la permanencia de la nieve en el suelo ha disminuido 20 días. El calentamiento global está influyendo en la permanencia de la cubierta nival y, por tanto, en la reducción de la disponibilidad hídrica (ibídem, 2005).

\section{La escorrentía subterránea subsuperficial en estiaje: las surgencias de montaña y el caudal base de los arroyos}

Si se considera que el caudal de los manantiales es escorrentía subterránea propiamente dicha, ésta asciende en todo el macizo de Peñalara a $40 \mathrm{~L} / \mathrm{s}$. Se remarca el carácter de estacionalidad de los caudales, tanto de arroyos como de manantiales. El aumento de la escorrentía subterránea subsuperficial es mucho mayor tras la fusión de la nieve, que recarga en manta estas formaciones de ladera. Destaca el drenaje subterráneo que genera el Macizo de Peñalara sobre los otros macizos del entorno de la Sierra del Guadarrama. Así, por ejemplo, en la margen izquierda del Eresma en Valsaín, los arroyos apenas tienen caudal base en estiaje.

El número y el caudal aportado por manantiales y arroyos se concentra entre los 1900 y los 2200 m (Fig. 15), íntimamente relacionados con la presencia y localización de los depósitos glaciares y periglaciares más importantes, que hacen de mantos acuíferos o subacuíferos apoyados sobre rocas impermeables metamórficas (Fig. 16). Aparte de este factor determinante, influye el aumento de la recarga por el aumento de la precipitación con la altitud, la disminución de la evapotranspiración, el incremento de las precipitaciones en forma de nieve, y la permanencia de ésta en el suelo, lo que aumenta el efecto regulador y el retraso de la infiltración. Este flujo subsuperficial es característico de montañas altas afectadas por la acción del hielo (Castillo y Fedeli, 2002).

Así, en la vertiente oriental del Macizo de Peñalara hay una aportación hídrica de escorrentía subterránea e hipodérmica de $28 \mathrm{~L} / \mathrm{s}$ que se asocia a las descargas de las reservas hídricas almacenadas en las 


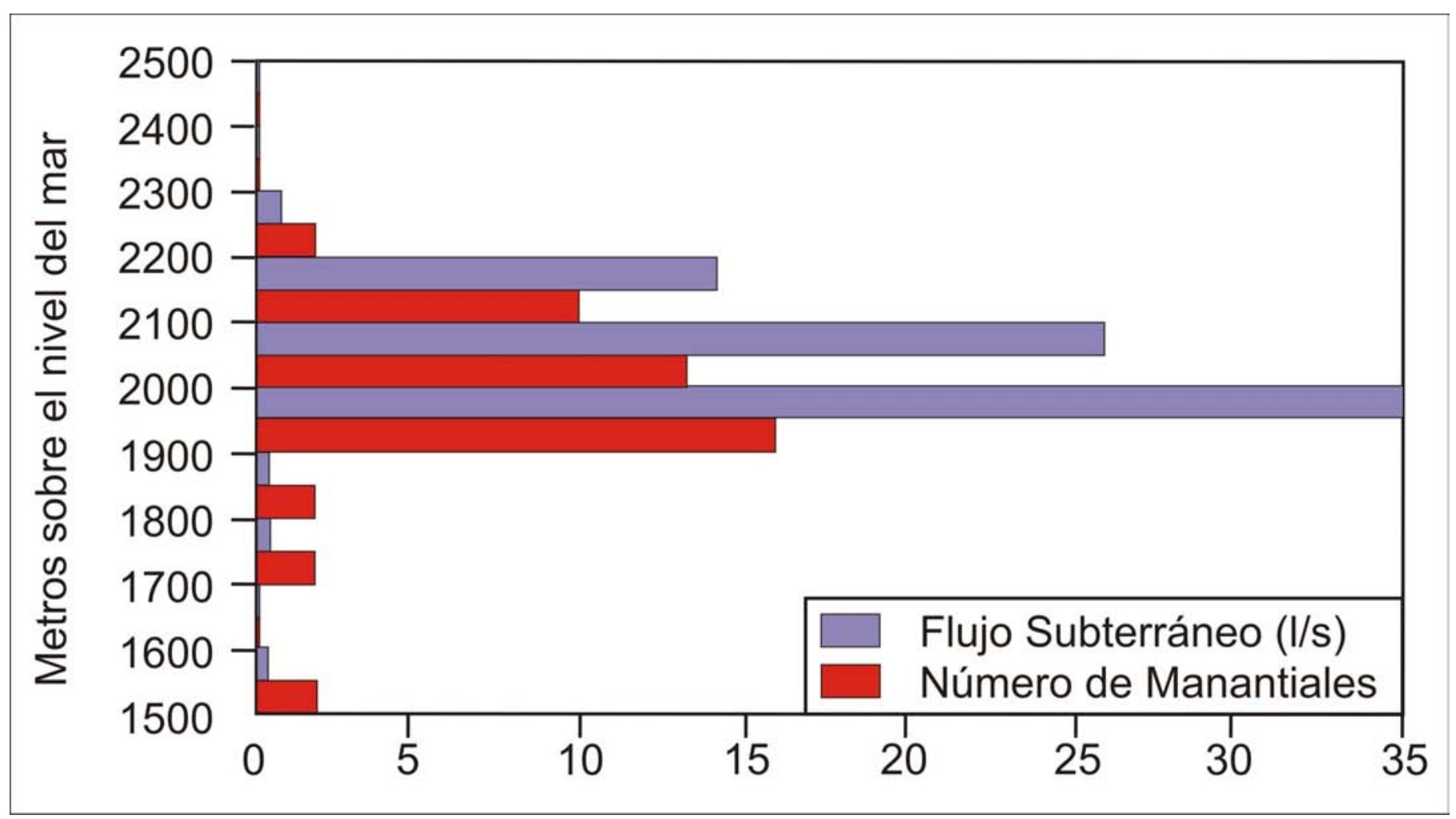

Figura 15. Histograma de caudales y número de manantiales en el macizo de Peñalara.

Figure 15. Bar chart of flow rates and number of springs in the Peñalara massif.

VERTIENTE NOROCCIDENTAL

VERTIENTE ORIENTAL

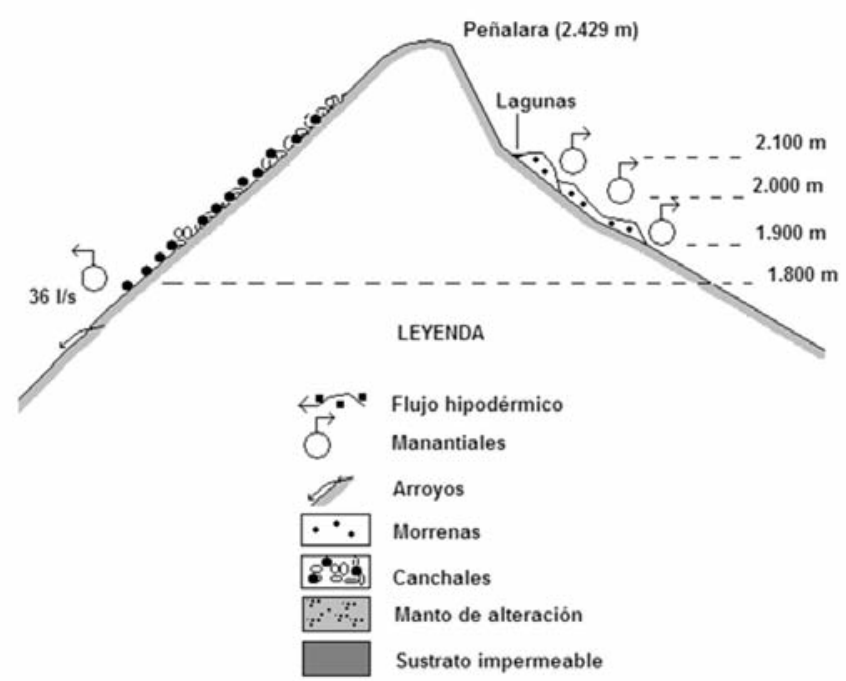

Figura 16. Esquema hidrogeológico que muestra la relación entre la situación altitudinal de los depósitos glaciares, periglaciares y zonas de alteración, con los manantiales y flujo hipodérmico para las dos vertientes del Macizo de Peñalara.

Figure 16. Hydrogeological schematic representation showing the relationship between the altitude of the glacial deposits, periglacial deposits and zones of alteration, with the springs and hypodermic flow for the two slopes of the Peñalara Massif. voluminosas morrenas glaciares, suelos hidromorfos y las lagunas de los Claveles y los Pájaros, que se van filtrando poco a poco. Si no hay mayor flujo subterráneo es porque en gran parte de esta vertiente aflora el sustrato rocoso, ya que se trata de formas de erosión glaciar que carecen de recubrimientos.

La vertiente noroccidental aporta un total de $36 \mathrm{~L} / \mathrm{s}$ y es la que genera más escorrentía subterránea en estiaje. En ello influye el papel que juega la nieve y la existencia de canchales muy permeables y potentes que también se recargan de las filtraciones de las corrientes de agua del deshielo en cabecera.

Respecto del control geológico de los manantiales, hay algunos que están condicionados por fracturas permeables del sustrato o intersección de las mismas, como ocurre en las fuentes de la zona de Cabeza de Gatos de Valsaín de Segovia (Sanz Pérez, 1998). Sin embargo, la mayoría se sitúan al pie de formaciones superficiales de ladera en el contacto con el sustrato impermeable, dando lugar a prados y cervunales. Es también muy frecuente que haya manantiales en el fondo de vaguadas que atraviesan canchales y otras formaciones de ladera, como son los arroyos de las lagunas de Peñalara. 
Javier G. Yélamos, et al., 2019. Las aguas subterráneas del Parque Nacional de la... Boletín Geológico y Minero, 130 (4): $743-772$

\section{Introducción al funcionamiento hidrogeológico de los humedales del Parque Natural de Peñalara}

Hay cuatro lagunas con turberas asociadas y suelos hidromorfos que tienen gran importancia ecológica, pues son las únicas lagunas glaciares de la Sierra del Guadarrama (De la Hera et al. 2013). Presentan una fauna muy característica, con especies únicas, y sus turberas sirven para conocer el clima pasado. Dadas su pequeña magnitud y volumen de agua, presentan un equilibrio hídrico muy sensible a estiajes, contaminación antrópica, colmatación, erosión en orillas, etc. (Toro y Montes, 1993; Granados et al. 2006) Según (FGUAM-AM, 1993 y 1997), el tiempo medio de residencia del agua en la Laguna de Peñalara es de 6-9 días. Esta laguna se aloja en un ombligo glaciar del sustrato.

La Laguna de los Claveles se encuentra en el contacto entre el sustrato y una morrena frontal o de glaciar rocoso y se filtra con facilidad. Presenta un emisario superficial que en estiaje no suele llevar agua. Las filtraciones ocurren lateralmente, alimentando a unas charcas próximas y otras más o menos alejadas, situadas en el contacto entre la morrena y el sustrato.

Entre esta última laguna y la de Peñalara, hay una serie de charcas, con suelos hidromorfos y turberas asociadas, apoyadas en el sustrato o en depósitos morrénicos, por lo que algunas tienen también filtraciones y se secan con rapidez. Muchas de ellas se alimentan de brotes y descargas subterráneas.

Algunas zonas húmedas se asocian a depresiones humedecidas por las aguas del deshielo: cervunales turbiformes y verdaderas turberas. Las hay también en cubetas de ombligos glaciares, aluvionados e inundados, de cierre de morena o de origen mixto. Hay otras asociadas a bordes de arroyos y charcas en hombreras. Hay lagunas de inundación efímera y charcas que mantienen una lámina de agua durante un largo periodo de tiempo, ya que están ligadas a la descarga de agua subterránea: esto es lo que ocurre en gran parte de las charcas de los circos glaciares de Peñalara, alimentadas de las descargas al pie de derrubios de ladera o a las filtraciones de la base de las morrenas.

\section{Papel de las aguas subterráneas en el área del Parque Nacional de Guadarrama}

\section{Introducción}

En apartados anteriores ya se ha indicado que los acuíferos comprendidos dentro del PNG se caracterizan por unos escasos recursos y reservas, con la excepción del acuífero sedimentario del Alto Valle del
Lozoya. Sin embargo, su papel no es despreciable, ya que durante el verano los cauces superficiales tienden a agostarse y en ese caso la mayor capacidad de regulación de las discretas aguas subterráneas da lugar a que tengan un papel más relevante. El caso es similar al de un oasis en medio del desierto; quizás el volumen de agua no es cuantitativamente elevado, pero cobra una gran importancia cuando no hay otro recurso del que abastecerse.

\section{Abastecimiento a núcleos de población}

De una manera muy sintética, el abastecimiento de agua a los pueblos de la Sierra de Guadarrama ha pasado por las siguientes etapas.

1) En un primer momento el abastecimiento se realizaba a partir de manantiales que brotaban dentro o muy cerca de los límites de la población, sobre los cuales se construía una fuente o al menos una arqueta. La finalidad era simplemente aportar el agua de boca. No se disponía de red de abastecimiento en las viviendas. Para el lavado de la ropa se recurría a cauces superficiales próximos o a una cacera y la mayor parte del agua disponible era empleada para riego de prados y huertas. La referencia a riego de huertos puede sonar un poco llamativa hoy en día, pero por citar un solo ejemplo, en el mapa topográfico 1:50000 publicado en 1880, las huertas ocupaban unas 130 ha alrededor de la localidad Lozoya.

2) Por crecimiento de la población se realizan captaciones tanto de aguas superficiales como subterráneas. Puede hacer su aparición un lavadero municipal dentro del casco urbano para facilitar esta tarea doméstica.

El principal requisito es que la toma de agua disponga de la suficiente altitud como para llegar a los depósitos reguladores por simple gravedad. Como ejemplo de sistema mixto, una de las fuentes de abastecimiento a Lozoya consistía en cinco arquetas de captación en otros tantos manantiales sobre gneises, que a su vez recogían el agua a cota más alta en el cauce del arroyo de Carretero, a través de un azud que dejo de estar en servicio al colmatarse con sus aluviales (Yélamos, 1986). En otros casos tan solo se recurría a aguas superficiales, tal como se dio en Los Molinos con el azud de los Barrancos que drena en la principal fuente del pueblo, la del León.

Como captación de aguas subterráneas merece citarse la mina de agua de Cercedilla, consistente en una galería que desde 1918 suministraba agua a las fuentes públicas de esa localidad.

Muy posiblemente, en la vertiente segoviana más húmeda y fría, la tendencia era a recurrir directamen- 
te a una toma de aguas superficiales, mientras que en la vertiente sureste madrileña con un clima menos húmedo, la tendencia era recurrir a captaciones de aguas subterráneas. El criterio de ubicación era simplemente la existencia de un manantial previo o de una zona encharcada, turbera o tolla. Un tipo de captación común consistía en tres zanjas de drenaje dispuesta en forma de pata de pájaro, orientadas aguas arriba y confluyendo en una arqueta enterrada donde las aguas subterráneas se decantaban; en la zona serrana, a esta operación se la denominaba "sangrar la tolla" o zona húmeda. En cualquier caso, la opción a escoger estaba en función de los recursos hídricos existentes en el municipio a una cota adecuada para una aducción por gravedad.

3) Introducción de suministro en las casas con lo que el consumo de agua se incrementa notablemente. Se realizan nuevas captaciones, tanto en aguas superficiales como subterráneas para cubrir la demanda ya que el sistema tiende a ser deficitario en verano. Los municipios de mayor entidad llegan incluso a disponer de un pequeño embalse para regulación de aguas superficiales, casos de Miraflores de la Sierra, Becerril y Cercedilla con los embalses de Miraflores, Maliciosa y Las Berceas respectivamente.

4) La última etapa acontece cuando ya prácticamente la totalidad de los recursos hídricos del municipio están captados, pero sufren una crisis en los veranos secos. Durante el estío los caudales en cursos superficiales y captaciones en manantiales se encuentran en valores mínimos a la vez que la demanda se incrementa por una población estival y surgen nuevas demandas por riego de jardines y llenado de piscinas, de manera que el sistema municipal resulta insuficiente. Para cubrir las crisis, los municipios madrileños se conectan a la red del CYII, como complemento al sistema de abastecimiento municipal. En el caso de la vertiente segoviana, las localidades de la mancomunidad de La Mujer Muerta pueden complementar su abastecimiento veraniego a partir del Embalse de Puente Alta, que en principio está destinado a Segovia capital (Ayuntamiento de Segovia, 2013).

Estas etapas reflejan la tónica general en la evolución del abastecimiento; de acuerdo con sus propias características, cada población ha podido tener una evolución distinta. En la localidad de la Cabrera, existiendo fuentes públicas de manantial, una buena parte de la población se autoabastecía mediante pozos excavados, no existiendo red de distribución de agua en las viviendas hasta que llegaron las conducciones del CYII. En Mangirón, la fuente pública estaba conectada al CYII desde 1934, posiblemente en compensación por estar en su municipio el embalse de El Villar y nunca dispuso de una red municipal abastecida por captaciones en manantiales (Yélamos et al., 1992).

Además del papel de abastecimiento a los núcleos serranos de población, lo exiguos recursos de aguas subterráneas son fuente de abastecimiento para un buen número de chalets con parcela, especialmente para aquellas viviendas de segunda residencia establecidas sin un ordenamiento urbanístico previo, sin conexión de redes generales de abastecimiento. Ante tales circunstancias, a los propietarios de una parcela no les quedaba más remedio que realizar dos pozos en su finca: uno para abastecimiento de agua y el segundo como pozo negro o una fosa séptica. Aunque los rendimientos en estos materiales no son altos, una captación capaz de aportar un caudal continuo de $0.1 \mathrm{~L} / \mathrm{s}$ es suficiente para cubrir las necesidades de agua de una vivienda unifamiliar, el llenado de una discreta piscina y el riego de una pequeña parcela.

Villarroya y Rebollo (1986), analizando el número de pozos registrados en cada uno de los municipios madrileños muestran como el mayor número de captaciones tiende a darse en municipios ocupados con sustrato plutónico y metamórfico ocupando los tres primeros puestos Pelayos de la Presa, Alpedrete y Torrelodones, con valores de 34, 23 y 18 pozos por $\mathrm{km}^{2}$, tratándose en la mayoría de los casos de pozos excavados. Aunque una elevada densidad de captaciones pueda interpretarse como abundancias de recursos de aguas subterráneas, en el caso que nos ocupa es más bien indicativo de la necesidad de cubrir una demanda donde los habitantes disponen de una parcela donde poder realizar el pozo.

Posiblemente la realización de pozos en las viviendas de segunda residencia fue catalizada por los siguientes factores: 1) problemas de abastecimiento que se daban durante los veranos en los municipios cubiertos por la extinta CASRAMA y 2) los que se podría denominar como "efecto simpatía"; un particular hace un pozo en la parcela de su chalet y acto seguido el vecino, al ver que el resultado es positivo, aunque sea bajo caudal, contrata la realización de otro en su predio.

Las mejores características del acuífero sedimentario del Alto Lozoya han dado lugar a que este haya jugado un papel más significativo en el abastecimiento a las cinco localidades asentadas sobre éste, si bien hoy en día todas tienen conexión con el suministro del Canal de Isabel II. Rascafría dispone de los manantiales kársticos de Molino y Batanes para suplir el abastecimiento, medida que solo se aplica en caso de necesidad ya que requiere de un bombeo para vencer un desnivel de casi $100 \mathrm{~m}$ entre los manantia- 
les y los depósitos reguladores. Dentro de ese municipio, a principios de los 80 se realizó un sondeo para reforzar el abastecimiento a la localidad de Oteruelo del Valle, sobre los terrígenos paleógenos sobre los que se asienta el depósito regulador, pero el caudal resulto insuficiente para compensar equiparlo (Yélamos, 1986); también dentro del mismo municipio de Rascafría, la urbanización Los Grifos tiene un sistema de abastecimiento particular a partir de las aguas subterráneas del acuífero sedimentario.

Antaño, la localidad de Alameda obtenía parte de su agua mediante una captación sobre un antiguo manantial, abastecido por el acuífero sedimentario; ésta venía a funcionar a modo de pozo excavado, pero de sección cuadrada, con un caudal del orden de $1 \mathrm{~L} / \mathrm{s}$. Posteriormente se realizó un pozo perforado profundo en el paraje del Cerco de la Fragua.

La localidad de Lozoya se abastecía mediante un complejo sistema con varios puntos de toma en arroyos y decenas de captaciones en manantiales sobre hard rocks, conduciéndose las aguas a los depósitos por gravedad. Para complementar el abastecimiento, en los meses de verano se bombeaba un pozo perforado realizado en 1972 por el extinto Servicio Geológico de Obras Públicas con una caudal de aforo inicial de 25 L/s. Un segundo pozo perforado, cercano al anterior no se llegó a equipar por la aparición de hundimientos en el terreno a modo de dolinas de 3-5 $m$ de diámetro y 2 $\mathrm{m}$ de profundidad durante el aforo inicial, lo que corrobora la naturaleza kárstica del acuífero.

Un caso peculiar es el abastecimiento al complejo de la cartuja de Santa María de EI Paular, cerca de la localidad de Rascafría. Éste se basa en un par de tomas de aguas superficiales en el arroyo de Santa María aguas arriba del complejo, pero también incluye una tercera toma de aguas subterráneas, mediante un qanat o viaje de agua; consiste en una galería que hace el doble papel de captación y de conducción hasta el punto de suministro, en este caso al monasterio. Parte del trazado de la galería se puede reconocer fuera del recinto de la Cartuja por la existencia de 3 pozos de registro tapados con pesadas piedras cónicas de granito (unos $400 \mathrm{~kg}$ cada una) denominadas capirotes (Fig. 17). La longitud total de viaje es de unos $450 \mathrm{~m}$ desarrollándose sobre los terrígenos de edad Paleógena que rellenan la fosa del Alto Valle del Lozoya (López Vera y López Camacho, 2017).

\section{Actividades recreativas y ganadería}

Sin ser condición sine qua non, la presencia de una pléyade de pequeños manantiales por toda la superficie es claramente un factor que favorecen las activi-

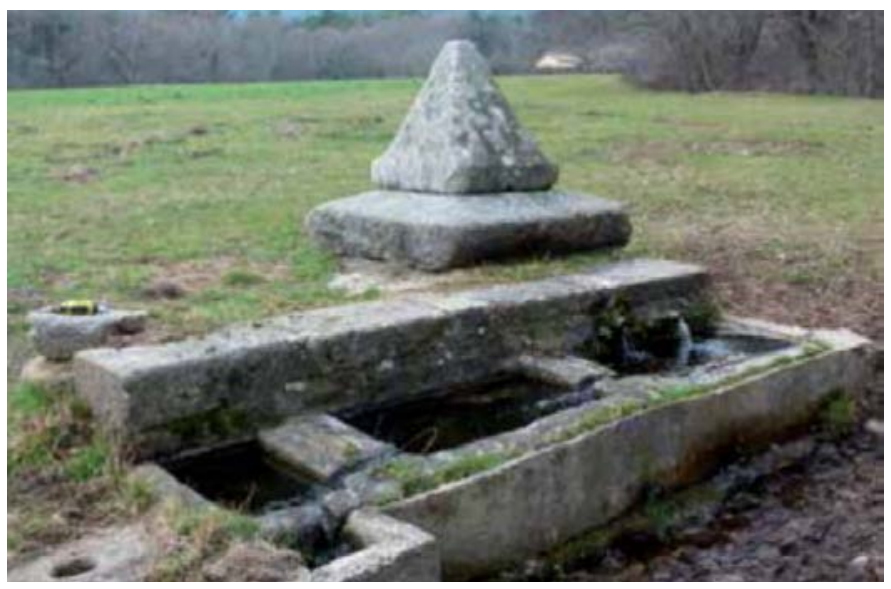

Figure 17. Capirote del viaje de abastecimiento a El Paular junto a abrevadero en el Prado de las Ovejas (López Vera y López Camacho, 2017).

Figure 17. "Capirote" of qanat for drinking water supply to El Paular, near a drinking trough for cattle in Prado de las Ovejas (López Vera y López Camacho, 2017).

dades recreativas y de ocio. Un área de descanso con mesas pierde una buena parte de su interés si no dispone de suministro de agua, y si en una actividad de senderismo se sabe que se pasa junto a una fuente de agua fresca es un peso a eliminar de la mochila, así como un punto ideal para realizar un descanso durante el recorrido.

Entre las decenas de fuentes con obra de fábrica existentes en el PNG, cabe destacar la de los Geólogos (Fig. 18a), situada cerca del puerto de Navacerrada; sin duda una de la más conocidas y visitadas ya que dispone de un parking anexo resultando sencillo el pararse y beber o recoger sus frías, muy poco salinas y no cloradas aguas. Que sepamos no existe en toda España otra fuente que sea homenaje a los profesionales de la geología, si bien esta no hace referencia directa al colectivo, sino a un grupo de cuatro pioneros en el estudio de la Sierra de Guadarrama (Fig. 18b). Se ha encontrado una referencia a otra "Fuente de los Geólogos" cerca de la localidad de Argañoso (León), pero al parecer se trata de una errata. En el frontal de la fuente aparece el escudo (dos martillos cruzados) del cuerpo de ingenieros de minas, que muy posiblemente fueron los responsables de la captación.

Otra fuente emblemática es la de Cossío (Fig. 18c) en lo alto del puerto de la Morcuera, en homenaje al pedagogo Manuel Bartolomé Cossío. La arqueta de toma se encuentra aguas abajo de una pequeña turbera y suministra agua tanto a la fuente como al vecino refugio de la Morcuera.

Esta circunstancia nos indica otro papel de las 

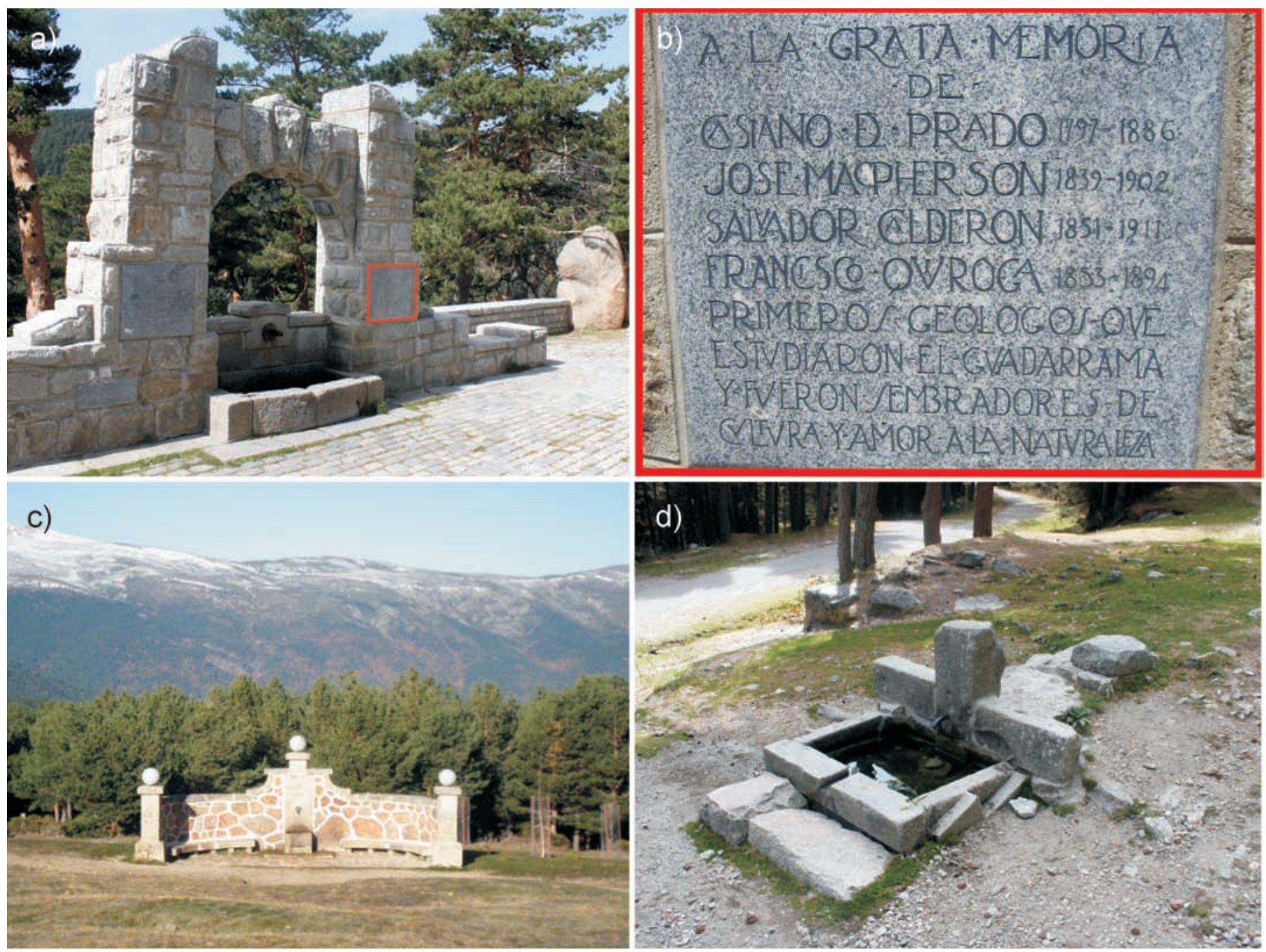

Figura 18. Algunas fuentes singulares del PNG. a) Fuente de los Geólogos. b) Placa en la Fuente de los Geólogos con los nombres de los científicos homenajeados. c) Fuente Cossio en lo alto del Puerto de la Morcuera, con las alineaciones montañosa de la Sierra de Guadarrama al fondo. d) Fuente de la Reina en el camino al Puerto de la Fuenfría.

Figure 18. Some singular springs in the PNG. a) Geologists spring. b) Plaque on the Geologists spring with the names of the honoury scientists. c) Cossio spring at the top of the Morcuera mountain pass with the Guadarrama Range in the background. $d$ ) Spring of the Queen on the way to the Fuenfría mountain pass.

aguas subterráneas: la posibilidad de abastecer a los refugios de montaña y en general pequeñas demandas dentro del PNG que se encuentran alejadas de las redes generales de abastecimiento y a cotas elevadas, como puede ser los depósitos de agua para los retenes contra los incendios, que frecuentemente también sirven de fuente para los visitantes; si no fuera por esos pequeños manantiales, sería más costosa la obtención del líquido elemento.

Entre las fuentes de la vertiente segoviana se puede destacar la Fuente de la Reina, no por su discreta obra de fábrica (Fig. 18d), sino por haber sido el punto de parada y descanso para la corte en sus desplazamientos veraniegos desde Madrid hacia el pala- cio de Valsaín, atravesando por el puerto de la Fuenfría, nombre por el que también se conoce a la fuente. De acuerdo con Mejías et al. (2015), el acuífero que la alimenta se debe a fracturas, brotando el agua en el contacto entre para y ortogneises.

En relación a la actividad ganadera, en los prados de la zona, salvo los cruzados o fronterizos a cauces superficiales, es una constante la presencia de una fuente con su pilón en el que pueda abrevar el ganado, a partir de una arqueta que capta un manantial o de un pozo excavado a mayor cota que el pilón, de manera que se drene por gravedad. Aunque el caudal sea de tan solo $0.1 \mathrm{~L} / \mathrm{s}$, es suficiente para cubrir la demanda de agua de medio centenar de vacas lecheras. 


\section{Papel ecológico}

Los arroyos, ríos y zonas húmedas del PNG presentan una gran variedad de fauna y flora. Todos los manantiales y descargas hipodérmicas asociadas a las formaciones geológicas superficiales que se han descrito anteriormente contribuyen en la Sierra a formar el caudal base y ecológico de los arroyos, y la existencia de cotos trucheros, por ejemplo, está favorecido por estas corrientes de agua subterránea más duraderas, como es el caso del arroyo de la Angostura (cabecera del rio Lozoya), del río Peñalara en Valsaín, etc.

Por otro lado, y según García París et al. (1999) y Martínez-Solano et al. (1999), en las zonas altas (1800$2430 \mathrm{~m}$ ) la fauna de anfibios es, sin duda, de la más diversa de Europa, pues hay 8 especies que se concentran sobre todo en el Parque de la Cumbre, Circo y Laguna de Peñalara, precisamente en los nacimientos de la mayor parte de los arroyos, humedales y manantiales, por lo que cualquier actuación que se haga en ellos puede tener mucha repercusión. Parece ser que el calentamiento global está aumentando la temporalidad de las zonas húmedas y encharcadizas (Bosch, 2005), con la consiguiente dificultad de reproducción de los anfibios, por lo que ha sido necesario la realización de actuaciones para mantener las láminas de agua de los arroyos (Bosch, 2005; Sancho, 2009).

Por debajo de los 1800 y hasta los $800 \mathrm{~m}$ de altitud, la fauna de anfibios de fresnedas, melojares $y$ pinares del pie y laderas de la Sierra, es también extraordinariamente rica. Muchos de ellos están habitando y aprovechan para reproducirse los pilones y abrevaderos de fuentes y zonas encharcadizas asociadas, así como charcos y lagunas de canteras abandonadas, por ejemplo, donde se retiene el agua de lluvia, o aflora el nivel freático.

EI PNG cuenta con una colonia de una especie muy singular y vulnerable de mariposa denominada Maculinea nausithous, que vive en prados húmedos de graminoides higroturbosos, formaciones herbáceas densas estructuradas en cepellones que con frecuencia están inundados (Viejo, 1998). Su conservación depende precisamente de la conservación de estos prados y del mantenimiento del nivel freático (ibídem, 1998), que por la situación de la colonia (alrededores de la urbanización Los Grifos), el posible nivel freático correspondería al acuífero sedimentario del AVL descrito.

Para finalizar este apartado, se puede citar una peculiar vegetación asociada a las denominadas aguas subterráneas de circulación profunda. En zona de descarga dan lugar a una zona local con ambiente alcalino y sódico en el que puede aparecen una vege- tación fuera de contexto, en concreto dos tipos de juncos, el Juncus acutus o junco espinoso (Fig. 19) y el Juncus maritimus. Ambos son característicos de ambientes salinos y costeros precisamente (maritimus hace referencia a próximo al mar), pero localmente se pueden encontrar en medio de los suelos ácidos de la Sierra de Guadarrama, al parecer por la descarga de esas aguas subterráneas (MartínLoeches y Yélamos, 2013).

\section{Aguas minerales y mineromedicinales}

Ya Prado (1862) en su pionera obra sobre la geología de Madrid deja constancia de la escasez de aguas minerales en la zona madrileña de la Sierra de Guadarrama; únicamente eran reconocidas tres: Manjirón, Fuente de la Sima (Colmenar Viejo) y la Fuente del Toro (EI Molar).

Las tres presentan carácter sulfhídrico, alta salini-

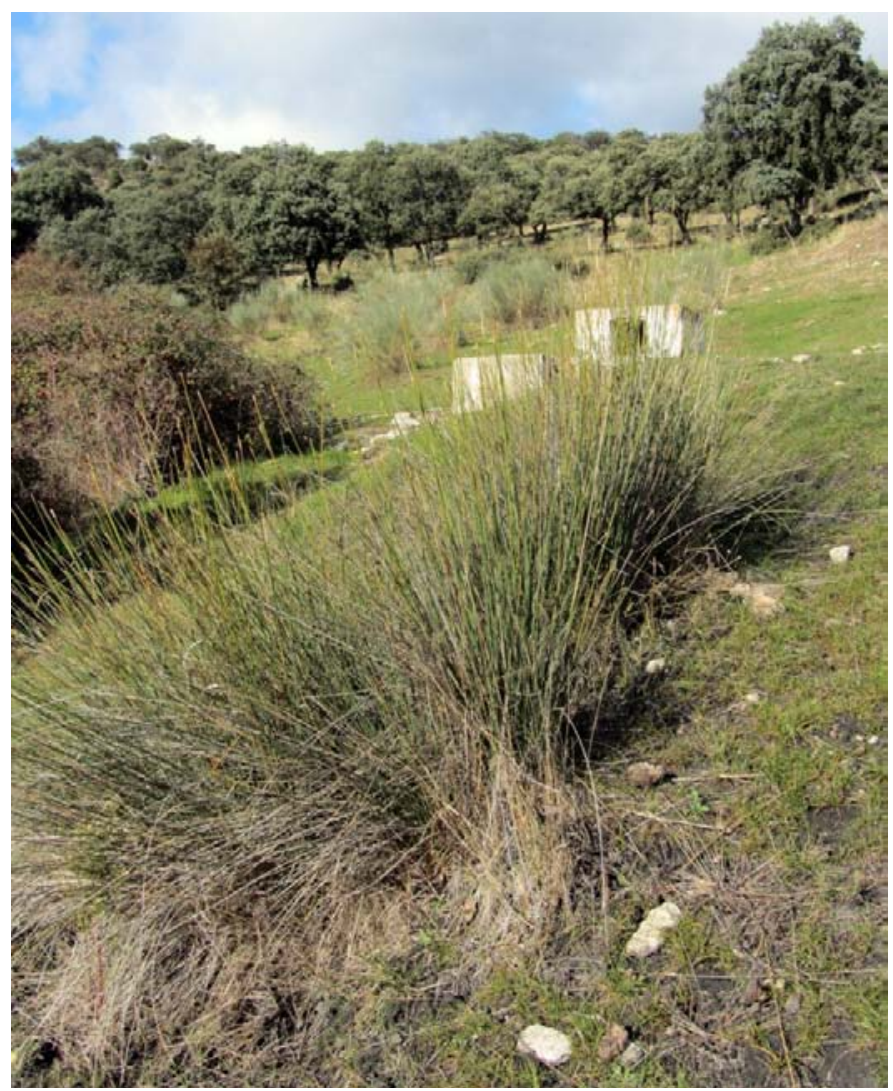

Figura 19. Matas de Juncus Acutus sobre granitos. En segundo plano la Fuente de la Sima cuyas aguas alcalinas son las posibles responsables de esta vegetación.

Figure 19. Bushes of Juncus Acutus on granite rocks. In the background the Sima spring, whose alkaline water could be the cause for this vegetation. 
dad en comparación con las aguas subterráneas someras y están sitas fuera de los límites del PNG, aunque si se considera válido el modelo conceptual de flujo de la figura 7, las cumbres del PNG vendrían a ser parte de su zona de recarga. La primera se encontraba junto a la margen derecha del rio Lozoya (Prado, 1862) y actualmente se encuentra cubierta por las aguas embalsadas por la presa de El Atazar. La Fuente de la Sima (Fig. 20a) tiene dos puntos de surgencia en sendos valles paralelos y aunque no se llegó a construir un balneario, consta que fue usada como medicinal y para baños (Rosel, 1865). Las aguas sulfurosas de la Fuente del Toro eran conocidas desde antiguo pues son descritas por Limón Montero (1697) y dieron lugar a la aparición de un establecimiento balneario (Fig. 20b) con planta de envasado anexa (Rodríguez Pinilla, 1897), que estuvo activo casi una década desde mediados del XIX hasta los años 40 del pasado siglo (Sánchez Ferré, 1992).

Prado (1862) hace referencia a otras dos captaciones más de aguas minerales en la parte madrileña de la Sierra de Guadarrama: una en el plutón granítico de La Cabrera y las aguas sulfurosas de Bustarviejo. De la primera en campo no hemos encontrado ningu-

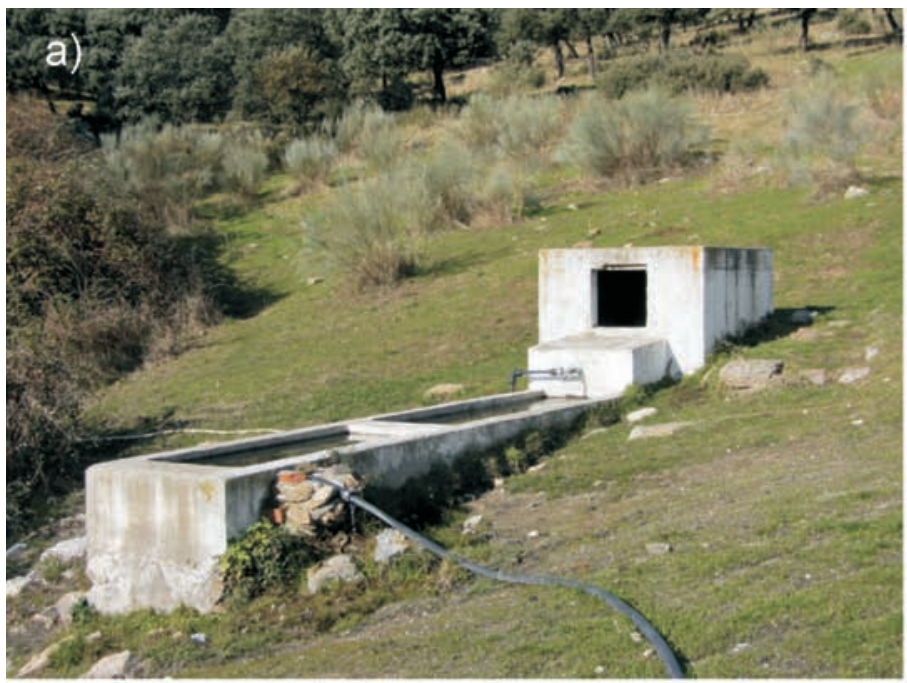

\section{b) BALNEARIO de 'EL MOLAR' AGUAS SULFIDOHDRTCO-SALINO-SULFATADAS}

cURació RaDicaL DE TODAS LAS EXFERMEDADES DE LA PIEL. Y APARATO RESPILATORIO


Figura 20. Algunas aguas minerales en la zona de estudio. a) Fuente oriental de la Sima. El abrevadero antiguamente se usó para baños. b) Hoja publicitaria del Balneario de la Fuente del Toro (Rodriguez Pinilla, 1897). c) Planta embotelladora de Bezoya en Hortigosa del Monte. Al fondo el valle en el que se encuentran las captaciones en manantiales. d) La Fuente sulfurosa de la Losa o Fuentesalá dentro de un área de recreo.

Figure 20. Some mineral waters in the study area. a) Eastern spring of La Sima. The trough was used for bathrooms in former days. b) Advertising leaflet of the Fuente del Toro Spa (Rodriguez Pinilla, 1897). c) Bezoya bottling plant in Hortigosa del Monte. In the background, the valley where the water uptake springs are located. d) The sulphurous spring of Losa or Fuentesalá, within a recreational area. 
Javier G. Yélamos, et al., 2019. Las aguas subterráneas del Parque Nacional de la... Boletín Geológico y Minero, 130 (4): 743-772

na referencia; quizás el burbujeo fuera simple gas nitrógeno, mientras que la segunda, como ya indicaba Prado, se corresponde con las aguas en un pozo minero, casi con toda seguridad la mina de plata de Bustarviejo, en la que desde el siglo XVII se extrajeron arsenopiritas (Jordá y Jordá, 2011), mineral que bien podría ser el origen del $\mathrm{SH}_{2}$ en esas aguas.

Junto a la localidad de Guadarrama se instaló el balneario de mayor transcendencia de todos los relacionados con el PNG: el Hotel-Balneario de La Alameda. El establecimiento se construye junto al manantial de la Porqueriza, a fin de aprovechar sus aguas que tenían fama de medicinales, y anexo a la colonia de verano establecida por iniciativa del célebre doctor Federico Rubio y Galí. Este complejo fue un lugar de veraneo de las élites madrileñas en las dos primeras décadas del siglo XX, llegando a conocerse como el "Panticosa de Madrid" (Soto, 2011a).

Aunque en los inicios se recurría a las aguas de la Porqueriza, dentro del subsuelo granítico del balneario brotaba un manantial y en 1905 se realizó un pozo de $4 \mathrm{~m}$ de profundidad dando unas aguas bicarbonatadas cálcicas $y$, lo que entonces se consideraba beneficioso para la salud "como las más radioactivas de España". Como el caudal del pozo lo permitía, también se inició una empresa de envasado de aguas que se vendían en un depósito establecido en Madrid, así como en farmacias madrileñas. La actividad balnearia cesó en 1930 y el edificio se destinó a varios usos entre ellos Academia de Cabos de la Guardia Civil (ibídem, 2011a).

Una última referencia a la balneoterapia fue el proyecto, no llevado a acabo, de restaurar el célebre albergue del Club Alpino de Navacerrada, y convertirlo en balneario de lujo, pero más concebido como centro de hidroterapia que no como un balneario s.s. con sus propias aguas medicinales.

En lo relativo a las aguas minerales envasadas, dentro del municipio de Lozoya se inició un proyecto de planta, llegándose a realizar 10 captaciones en manantiales sobre gneises de los 23 que tenía adjudicados, pero finalmente no llego a entrar en servicio y las captaciones se incorporaron al sistema de abastecimiento local de la población de Lozoya (Yelamos, 1986).

Cerca de los límites del PNG cabe citar otras plantas de envasado. La principal era la marca Fonsana que obtenía sus aguas (actualmente está fuera de servicio) a partir de cinco pozos a rotopercusión de unos 25-35 m sobre el plutón granítico de La Cabrera. La segunda en Moralzarzal, donde se envasó el agua denominada La Fé (y la Fé Perseverante) en el Portillo de la Mina, que fue vendida en farmacias madrileñas. La captación calificada como arseniacal y ferrugino- sa, se encontraba asociada a una mina de plata y fue declarada minero-medicinal en 1891. Las aguas también dieron lugar a un discreto edificio balneario, al parecer, en uso durante el primer tercio del siglo pasado, al que acudían los agüistas desde Moralzarzal (Soto, 2011b).

En la vertiente segoviana de la Sierra de Guadarrama la presencia de aguas mineromedicinales es también escasa. En la recopilación de balnearios y aguas minerales de Sánchez Ferré (1992) no se hace referencia a ningún establecimiento de este tipo en la vertiente segoviana de la Sierra de Guadarrama, y tampoco se cita agua medicinal alguna en toda la provincia de Segovia.

Sin embargo, es en esta vertiente noroeste del PNG donde se encuentran las captaciones de agua para una de las principales marcas de aguas envasadas en España: Bezoya, con una producción de unos 500 millones de litros en el año 2015. Declarada mineral en 1972, se inició su explotación en la planta de Ortigosa del Monte (Fig. 20c) a partir del manantial de La Beceda, para posteriormente incrementarse los recursos a partir de un rosario de zanjas de drenaje sobre los rocas metamórficas y graníticas dentro de la cuenca de alimentación del río Milanillos.

Posiblemente a causa de la baja capacidad de regulación de los acuíferos sobre hard rocks, junto con el incremento de la demanda, se puso en marcha una segunda planta embotelladora sita junto a la localidad de Trescasas a partir del agua denominada "Siete Valles", declarada mineral natural en 1994. Esta también dispone de captaciones en manantiales a partir de zanjas drenantes ubicadas sobre rocas metamórficas de la Sierra de Guadarrama, en este caso en la cuenca del río Cambrones.

Las captaciones de aguas subterráneas de ambas plantas disponen de sus correspondientes perímetros de protección, dentro de los límites de la zona periférica de protección del PNG, lo que viene a suponer una garantía adicional de conservación de la calidad de esas aguas. Su ubicación puede verse en la figura 21 en la que también aparecen el resto de las aguas minerales comentadas.

En una posición similar a las ya comentadas fuentes de la Sima y el Toro, el contacto entre las hard rocks de la Sierra y los sedimentos de relleno de cuenca terciaria, pero en este caso la del Duero, parece en la vertiente norte el manantial medicinal de La Losa o Fuentesalá. Al igual que las otras dos, se trata de agua de carácter sulfuroso y muy posiblemente son aguas de circulación profunda. En este caso, sí que el manantial se encuentra dentro del área de influencia socioeconómica del PNG; antaño dio lugar a un pequeño establecimiento balneario (Zelich y 


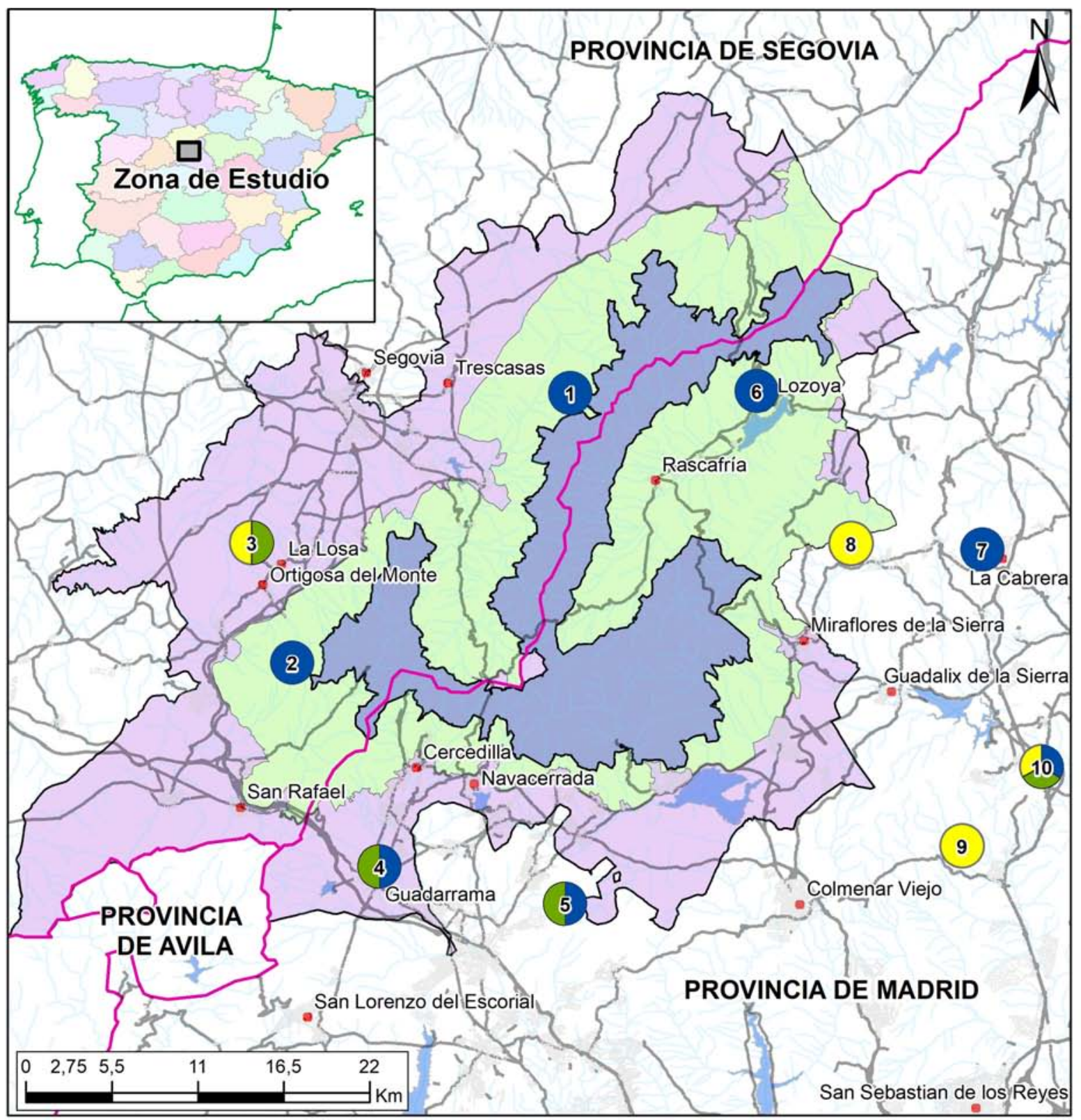

\section{Leyenda}

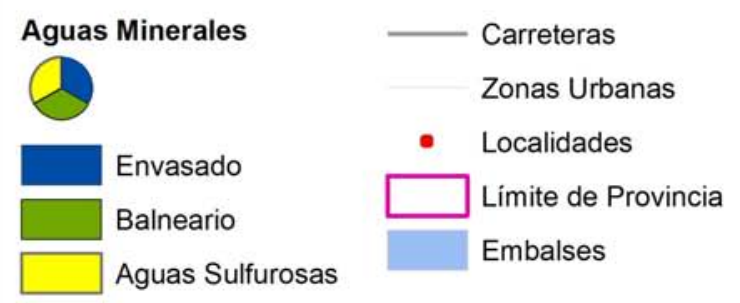

Red Fluvial

Parque Nacional de la Sierra de Guadarrama

Zona Periférica de Protección P.N.S. Guadarrama

Área de Influencia Socioeconómica del P.N.S.G.

Figura 21. Situación de las aguas minerales citadas en el texto. 1. Bezoya Trescasas, 2. Bezoya Ortigosa del Monte, 3. Fuente Salá, 4. Balneario de la Alameda, 5. La Fe en Moralzarzal, 6. Proyecto de planta embotelladora en Lozoya, 7. Fonsana, 8. Mina de plata de Bustarviejo, 9. Fuente la Sima, 10. Balneario de la fuente del Toro.

Figure 21. Geographic location of the mineral waters cited in the text. 1. Bezoya Trescasas, 2. Bezoya Ortigosa del Monte, 3. Salá spring, 4. La Alameda spa, 5. La Fe in Moralzarzal, 6. Bottling plant project in Lozoya, 7. Fonsana, 8. Bustarviejo silver mine, 9. La Sima spring, 10. Spa of the Toro spring. 
Javier G. Yélamos, et al., 2019. Las aguas subterráneas del Parque Nacional de la... Boletín Geológico y Minero, 130 (4): $743-772$

Sánchez San Román, 2009) mientas que hoy en día es la fuente de agua para un área de recreo (Fig. 20d) al norte del segoviano municipio de La Losa.

\section{Consideraciones finales}

Si nos remontamos a varias décadas atrás, los escasos estudios que hacían referencia a las aguas subterráneas en la región el PNG, pero en un contexto de estudio regional (no parece que haya, o no se han encontrado, trabajos específicos), se limitaban a indicar las generalidades que sobre la hidrogeología en hard rocks podían tomarse de cualquier manual. Frases del estilo: son materiales impermeables, solo dejan pasar agua a través de grietas, diaclasas o juntas en los que los caudales aumentan y disminuyen rápidamente por lo que no están alimentados por grandes acuíferos.

Esta situación ha tenido un notable cambio, tal como se refleja en el estudio de recopilación y síntesis de las páginas anteriores. Gracias a la realización de grandes infraestructuras, como los estudios previos para un sincrotrón y, sobre todo, la realización de un largo y profundo túnel para un tren de alta velocidad a través de las rocas endógenas del PNG, se ha obtenido una gran información de tipo hidrogeológico. Esto unido a la realización de varias tesis doctorales desde universidades madrileñas, ha aportado una nueva luz sobre esta temática. Quizás, el aspecto más novedoso sea la confirmación de ese flujo subterráneo profundo, de muy bajo caudal, pero que acontece a través del conjunto de discontinuidades que atraviesan el macizo rocoso, cuyo modelo conceptual de flujo parece ajustarse al propuesto por Toth (1962, 1963) para cuencas sedimentaras; ese mismo flujo es responsable de la aparición de aguas subterráneas con una composición química peculiar, muy evolucionada, a la vez que sus descargas en superficie pueden ser las responsables de la creación de un medio ambiente en el que aparezcan especies vegetales fuera de su ámbito más habitual.

En relación a los aguas subterráneas someras, cabe destacar el papel que han jugado para cubrir pequeñas demandas $y$, aun hoy en día, lo siguen teniendo como apoyo a las actividades ganaderas, y de ocio y recreo que se desarrollan en el PNG, permitiendo el establecimiento de fuentes y abrevaderos en puntos donde sería inviable, o muy costoso, a partir de las redes generales de abastecimiento.

No obstante, queda una gran labor a futuro. Con vistas a la conservación del PNG, sería deseable la realización de estudios hidrogeológicos de detalle, con el establecimiento de redes de control de la can- tidad y calidad de las aguas subterráneas, principalmente en el PNP donde se ubican una serie de humedales de alta montaña incluidos en el Convenio Internacional de Ramsar.

\section{Agradecimientos}

Se agradece a ADIF las facilidades prestadas en el acceso a la información relativa al túnel del tren de alta velocidad, que atraviesa el PNG, así como a los ingenieros Luis Pinillos y Davor Smic por compartir su experiencia en la realización del túnel. También se quiere agradecer la labor de dos revisores anónimos, cuyos comentarios y sugerencias han mejorado notablemente la calidad de este trabajo, así como al Editor por su paciencia a lo hora de incrementar los plazos de entrega del presente trabajo.

\section{Referencias}

Acaso, E., Centeno, J.D. y Pedraza, J. de. (1998). Nuevas aportaciones al modelo evolutivo del glaciar de Peñalara (Sistema Central Español). In A. Gómez et al. (Eds.): Investigaciones recientes de la Geomorfología Española. Univ. Barcelona. 691-696.

Ayuntamiento de Segovia 2013. Convenio para la cesión por el Ayuntamiento de Segovia de agua de la concesión de "Puente Alta" a la mancomunidad "La Mujer Muerta". Expediente: 2054/2007, 7 pp.

Bosch, J. (2005). Actuaciones recientes para la conservación de los anfibios de Peñalara. Quintas Jornadas Científicas del Parque Natural de Peñalara y del Valle de El Paular. El Paular (Rascafría). Comunidad de Madrid. Consejería de Medio Natural. Dirección General del Medio Natural. Madrid., pp.53-65.

Caballero, S. 2013. Análisis de la variación de la calidad química del agua en la cuenca alta del río Lozoya. Trabajo de Fin de Grado, inédito. Universidad Autónoma de Madrid, $43 \mathrm{pp}$.

CAM 1986. Mapa litológico de Madrid a escala 1:200000. Consejería de Agricultura y Ganadería, memoria 47 pp.

Capote, R. 2005. La Geología del proyecto del túnel del Guadarrama. En Túnel de Guadarrama. Coord. José Miguel Fernández de Castro. Entorno Gráfico. Móstoles, Madrid. 580 pp.

Castillo, A. y Fedeli, B. 2002. Algunas pautas del comportamiento hidrogeológico de rocas duras afectadas por glaciarismo y periglaciarismo en Sierra Nevada (España). Geogaceta, 32, 195-197.

CHT 2015. Plan hidrológico de la parte española de la Demarcación Hidrográfica delTajo. Memoria 130 pp.

Corchón, F. 1976. Estudio hidrogeológico del Cretácico en los alrededores de Torrelaguna (Madrid y Guadalajara). Boletín de Informaciones y Estudios del Servicio Geológico de Obras Públicas, 40, 189 pp. 
ENRESA 1996. El Berrocal Project. Characterization and Validation of Natural Radionuclide Migration Processes under Real Conditions on the Fissured Granitic Environment. Topical Reports, 6 volumes, Madrid.

España 2013a. Ley 7/2013, de 25 de junio, de declaración del Parque Nacional de la Sierra de Guadarrama. Boletín Oficial del Estado 152, 47795-47852.

España 2013b. Real Decreto 478/2013, de 21 de junio, por el que se aprueba el Plan Hidrológico de la parte española de la Demarcación Hidrográfica del Duero. Boletín Oficial del Estado 149, 46840-47010.

FGUAM-AM (1993). Bases limmológicas para la gestión del Sistema Lagunar del Parque Natural de la Cumbre, Circo y Lagunas de Peñalara. Parque Natural de Peñalara. Fundación General UAM- Agencia de Medio Ambiente, $216 \mathrm{pp}$.

FGUAM-AM (1997). Laguna de Peñalara. Seguimiento limmológico y control de las medidas adoptadas en la gestión del Parque Natural. Fundación General UAMConsejería de Medio Ambiente y Desarrollo Regional, 130 pp.

García-París, M., Martínez-Solano, I. y Bosch, J. (1999). Anfibios de la sierra del Guadarrama: singularidad y conservación. Segundos Encuentros Científicos del Parque Natural de Peñalara y del Valle de El Paular El Paular (Rascafría). Comunidad de Madrid. Consejería de Medio Natural. Dirección General del Medio Natural. Madrid., pp 33-41

GIF 2001. Nuevo Acceso ferroviario al Norte y Noroeste de España. Tramo Soto del Real-Segovia. Informe interno, documento 1, volumen V, anexo 3 (1). Madrid, 373 pp.

Granados, I., Toro, M. y Rubio-Romero, A. 2006. Laguna Grande de Peñalara, 10 años de seguimiento limnológico. Comunidad de Madrid, Consejería de Medio Ambiente y Ordenación delTerritorio. Dirección General del Medio Natural. Madrid, 185 pp.

Guimerá J, Carrera J, Holmes D, Rivas P, Tallos A \& Bajos C 1993. Preliminary analysis of the hydrogeology of "El Berrocal" experimental site: Hydrogeology of Hard Rocks, Proceedings. XXIV th Congress, International Association of Hydrogeologists, Oslo, 225-238.

De la Hera, A., Villarroya, F., Durán, J.J., Fornés, J.M., García de Domingo, A. y Morales, R. 2013. Aspectos hidrogeológicos de los humedales Ramsar de alta montaña en España. Bol. R. Soc. Esp. Hist. Nat. Sec. Geol., 107, p. 63-74.

IGME 1981a Atlas hidrogeológico de Madrid - Mapa hidrogeológico a escala 1:200000. Madrid.

IGME 1981b Atlas hidrogeológico de Madrid - Mapa de orientación al vertido de residuos sólidos urbanos a escala 1:200000, Madrid.

ITGE, 1988. Atlas geocientífico del medio natural de la Comunidad de Madrid. Memoria 83 pp. + 15 mapas.

ITGE 1989. Las Aguas Subterráneas en España. Estudio de Síntesis. $1^{\mathrm{a}}$ edición, 2 tomos, 591 pp.

ITGE 1990. Mapa geológico de España, a escala 1:50000. Hoja 508 Cercedilla. Memoria 104 pp. Madrid.

ITGE 1991. Mapa Geológico de España a escala 1:50000. Hoja 484 Buitrago de Lozoya. Memoria 105 pp. Madrid.

ITGE 1998. Mapa geológico de España, a escala 1:50000. Hoja 483 Segovia. Memoria 135 pp. Madrid.
Jordá, L y Jordá, R. 2011. La mina de plata de Bustarviejo 500 años de historia bajo tierra. Comunidad de Madrid y Ayuntamiento de Bustarviejo, 127 pp.

Karampaglidis, Th., Benito Calvo, A., Pérez-González, A., Baquedano, E. y Arsuaga, J.L. 2012. Secuencia geomorfológica y reconstrucción del paisaje durante el Cuaternario en el valle del río Lozoya (Sistema Central, España). Boletín de la Real Sociedad Española de Historia Natural Sección Geología, 105 (1-4), 149-162.

Limón Montero, A. 1697. Espejo cristalino de las aguas de España; hermoseado y guarnecido, con el marco de variedad de fuentes y baños. Impreso por Francisco García Fernández, Alcalá, 432 pp.

López Vera, F. 1985. Las aguas subterráneas en Madrid. Colección PIAM, 7, 198 pp. Canal de Isabel II. Madrid.

López Vera, F. y López Camacho, B. 2017. Abastecimiento histórico de agua al monasterio de El Paular: un qanat en la Sierra del Guadarrama (Madrid, España). Boletín Geológico y Minero, 128 (1), 193-206.

Martín-Loeches, M. 1995. Hidrogeología de las rocas ígneas y metamórficas de un sector de la Cuenca hidrográfica del río Alberche y su relación con las aguas subterráneas de la cuenca de Madrid. Tesis doctoral, Universidad de Alcalá de Henares.

Martín-Loeches, M. and Yélamos, J. G. 2013. Relationship between certain phreatophytic plants and regional groundwater circulation in hard rocks of the Spanish Central System. In: Ribeiro, L., Stigter, T.Y., Chambel, A., M. T. Condesso de Melo, Monteiro, J. P. and Medeiros, A. Groundwater and Ecosystems. CRC Press, IAH Selected Papers on Hydrogeology, 281-294.

Martínez-Solano, I., Bosch, J. y García-París, M., 1999. Los anfibios de Peñalara: evaluación de su estado de conservación y bases para su gestión. Segundos Encuentros Científicos del Parque Natural de Peñalara y del Valle de El Paular. El Paular (Rascafría). Comunidad de Madrid. Consejería de Medio Natural. Dirección General del Medio Natural. Madrid, pp 52-64.

Mejías, M., Fernández-San Miguel, M., Vías-Alonso, J., Castro-Quiles, A. \& Del Pozo, J. 2015. El Agua: de las Cumbres a los Valles. En: M. Mejías, Ed. El Parque Nacional de la Sierra de Guadarrama: cumbres, paisaje y gente. pp. 151-227. IGME-OAPN. Madrid.

Palacios, D. y Andrés de Pablo, N. (2000). Morfodinámica supraforestal actual en la Sierra de Guadarrama y su relación con la cubierta nival: el caso de Dos HermanasPeñalara. En: Procesos y formas periglaciares en la montaña mediterránea, pp. 235-364.

Palacios, D. y Andrés de Pablo, N. 2005. Relación entre dinámica nival y erosión en el Parque Natural de Peñalara y áreas próximas. Quintas Jornadas Científicas del Parque Natural de Peñalara y del Valle de El Paular. El Paular (Rascafría). Comunidad de Madrid. Consejería de Medio Natural. Dirección General del Medio Natural. Madrid, pp. 95-137.

Prado, C. de 1862. Descripción física y geológica de la provincia de Madrid. Imprenta Nacional, Madrid, 352 pp.

Rodríguez Pinilla, H. 1897. Guía del bañista. El Molar (Fuente del Toro). Imprenta de los hijos de José M. Ducazcal, Madrid, 32 pp. 
Rosel, C. 1865. Crónica de la provincia de Madrid. Editores Ronchi, Vitturi y Grilo, 250 pp.

Sánchez Ferré, J. 1992. Guía de establecimientos balnearios de España. Dirección General para la Vivienda y Arquitectura del Ministerio de Obras Públicas y Transportes, $357 \mathrm{pp}$.

Sancho, V. 2009. Restauración de hábitats prioritarios para los anfibios. Séptimas jornadas científicas del Parque Natural de Peñalara y del valle de El Paular. El Paular (Rascafría). Comunidad de Madrid. Consejería de Medio Natural. Dirección General del Medio Natural. Madrid, pp.35-45.

Sanz Herráiz, C. 1988. El relieve del Guadarrama Oriental. Consejería de Política Territorial. Comunidad de Madrid. Madrid, $547 \mathrm{p}$

Sanz Pérez, E. 1998. Estudio hidrogeológico del Túnel de Guadarrama para el AVE. ADIF. Fundación Agustín de Betancourt. ETSICCP, UPM, Madrid (Informe Interno).

Sanz Pérez, E. 2004. Caracterización del flujo subterráneo de los depósitos glaciares, periglaciares, áreas alteradas y zonas húmedas del Macizo de Peñalara (Sierra del Guadarrama, Sistema Central Español). VIII Simposio de Hidrogeología. Asociación Española de Hidrogeólogos. Zaragoza (España). 18-22 oct. 2004. Libro de comunicaciones. pp: 43-52.

SGOP 1969. Informe acerca del estudio del terreno mediante sondeos de reconocimiento para el emplazamiento de un sincrotrón de protones de $300 \mathrm{GeV}$, en El Escorial (Madrid). Informe inédito, memoria 8 pp., $\mathrm{n}^{\circ}$ de registro 993. Servicio Geológico de Obras Públicas. Madrid.

SGOP 1982. Posibilidades de suministro con aguas subterráneas de Rascafría, Oteruelo, Alameda del Valle y Pinilla del Valle. Informe inédito, memoria 11 pp., $\mathrm{n}^{\circ}$ de registro 1984. Servicio Geológico de Obras Públicas. Madrid.

SGOP-ITGE, 1990. Unidades Hidrogeológicas de la España peninsular e Islas Baleares. Síntesis de sus características y mapa a escala 1:1.000.000. Boletín de Informaciones y Estudios del Servicio Geológico de Obras Públicas, 52, 32 pp.

Soto, M. A. 2011a. Agua, salud y sociedad en la sierra de Guadarrama, 1890-1936. El manantial de aguas mineromedicinales de la porqueriza y el balnearismo en Guadarrama (Comunidad de Madrid). Espacio, Tiempo y Forma, serie VI, Nueva época. Geografía, 4 y 5, 177-194.

Soto, M. A. 2011b. Dudas sobre La Fe en el Portillo de La Mina. Historia de Moral y Zarzal. 25/09/17, http://historiasdemoralzarzal.blogspot.com.es/2011/08/dudas-razonables-en-el-portillo-de-la.html
Toth, J. (1962). A theory of groundwater motion in small drainage basins in Central Alberta, Canada. Journal of Geophysical Research, 67 (11), 4372-4387.

Toth, J. (1963). A theorical analysis of groundwater flow in small drainage basins. Journal of Geophysical Research, 68 (16), 4795-4812.

Viejo, J. L. 1998. Las mariposas de Peñalara y del valle del Lozoya. Primeros Encuentros Científicos del Parque Natural de Peñalara y del Valle de El Paular. El Paular (Rascafría). Comunidad de Madrid. Consejería de Medio Natural. Dirección General del Medio Natural. Madrid, pp.163-171.

Villarroya, F. I. y Rebollo, L. 1986. Las captaciones de aguas subterráneas de la provincia de Madrid. In: Llamas, M.R. (Coord.), Jornadas sobre la explotación de las aguas subterráneas en la Comunidad de Madrid. Colección PIAM, 12, 255-265. Canal de Isabel II. Madrid.

Villarroya, F. I., Yélamos, J. G., Molina, M.A. and Sanz, E. 2006. Hydrogeology of igneous and metamorphic rocks in the Guadarrama Sierra tunnel of the Madrid-Segovia high velocity railway (Spain) in Chambel, A. Proceedings of the $2^{\text {nd }}$ Workshop of the IAH Iberian Regional Working Group on Hard Rock Hydrogeology, 189-200.

Yélamos, J. G. 1986. Estudio de alternativas y mejoras de abastecimiento a las poblaciones de Rascafría, Oteruelo, Alameda del Valle, Pinilla del Valle, Lozoya, Braojos, Robregordo y Canencia. Informe inédito. Patronato Madrileño de Áreas de Montaña, 55 pp.

Yélamos, J. G. 1991. Hidrogeología de las rocas plutónicas y metamórficas en la vertiente meridional de la Sierra de Guadarrama. Tesis Doctoral. Universidad Autónoma de Madrid. 358 pp.

Yélamos, J. G., Herráez, I y Villarroya, F. I. 1992. Importancia social de las aguas subterráneas en materiales de baja permeabilidad: rocas plutónicas y metamórficas en la vertiente meridional de la Sierra de Guadarrama (provincias de Madrid y Guadalajara). V Simposio Nacional de Hidrogeología, XV, Alicante, 163-176.

Yélamos, J. G. 1997. Hard rocks hydrogeology in the center sector of Guadarrama Mountains (Spanish Central System) in Yélamos, J. G. and Villarroya, F. I. Hydrogeology of Hard Rocks. Spanish Group of International Association of Hydrogeologists, pp. 247265.

Zelich, C. y Sánchez San Román, F. J. 2009. Guía de las aguas de Castilla y León. Aguas minerales naturales y termales. Caja Duero, Ediciones Tempora, Salamanca, $273 \mathrm{pp}$.

Recibido: julio 2018

Revisado: septiembre 2018

Aceptado: febrero 2019

Publicado: diciembre 2019 